\title{
3. Polos e fluxos de deslocamento de pacientes para internação hospitalar e procedimentos selecionados no Sistema Único de Saúde
}

\author{
Diego Ricardo Xavier \\ Vanderlei Pascoal de Matos \\ Mônica de Avelar Figueiredo Mafra Magalhães \\ Jaime Gregorio Bellido \\ Wisley Velasco \\ Francisco Viacava
}

\section{SciELO Books / SciELO Livros / SciELO Libros}

XAVIER, D.R., MATOS, V.P., MAGALHÃES, M.A.F.M., BELLIDO, J.G., VELASCO, W., and VIACAVA, F. Polos e fluxos de deslocamento de pacientes para internação hospitalar e procedimentos selecionados no Sistema Único de Saúde. In: NORONHA, J.C., LIMA, L.D., CHORNY, A.H., DAL POZ, M.R., and GADELHA, P., eds. Brasil Saúde Amanhã: dimensões para o planejamento da atenção à saúde [online]. Rio de Janeiro: Editora FIOCRUZ, 2017, pp. 113-149. ISBN: 978-65-5708-090-0. https://doi.org/10.7476/9786557080900.0005.

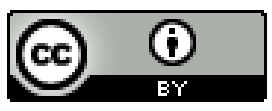

All the contents of this work, except where otherwise noted, is licensed under a Creative Commons Attribution $\underline{4.0 \text { International license. }}$

Todo o conteúdo deste trabalho, exceto quando houver ressalva, é publicado sob a licença $\underline{\text { Creative Commons }}$ Atribição 4.0.

Todo el contenido de esta obra, excepto donde se indique lo contrario, está bajo licencia de la licencia $\underline{\text { Creative }}$ Commons Reconocimento 4.0. 


\title{
POLOS E FLUXOS DE DESLOCAMENTO DE PACIENTES PARA INTERNAÇÃO HOSPITALAR E PROCEDIMENTOS SELECIONADOS NO SISTEMA ÚNICO DE SAÚDE
}

\author{
Diego Ricardo Xavier, Vanderlei Pascoal de Matos \\ Mônica de Avelar Figueiredo Mafra Magalhães \\ Jaime Gregorio Bellido, Wisley Velasco \\ Francisco Viacava
}

A extensão territorial do Brasil, a história e o dinamismo de sua ocupação, a grande diversidade de biomas e a utilização de seus espaços colocam grandes desafios para a organização equitativa e integrada de recursos para atendimento das necessidades sociais de sua população. No caso das respostas aos problemas de saúde, a multiplicidade de recursos requeridos, a diversidade de sua complexidade tecnológica e sua necessária articulação e integração, o exame de sua distribuição espacial e o uso que a eles é dado, são essenciais para uma apreciação de sua capacidade presente e planejamento de longo prazo.

No contexto da iniciativa de prospecção estratégica do sistema de saúde, articulada pela Fundação Oswaldo Cruz, são discutidos e reafirmados princípios que devem presidir as políticas de saúde no país (Noronha \& Pereira, 2013). No caso específico da distribuição territorial, embora a lei n. 8.080/1990 tenha estabelecido em seu artigo $8^{\circ}$ que "as ações e serviços de saúde, executados pelo Sistema Único de Saúde (SUS) (...) serão organizados de forma regionalizada e hierarquizada em níveis de complexidade crescente" (Brasil, 1990), apenas a partir do fim dos anos 1990 têm início, em escala nacional, os processos formais de definição de regiões de saúde (Lima et al., 2012). Esse processo se desenvolveu dentro dos limites das unidades federadas por agrupamentos de municípios agregados fundamentalmente por vizinhança, existência de polos socioeconômicos e, em certa medida, pela distribuição da oferta dos diferentes tipos de serviços de saúde.

A acelerada mudança demográfica e epidemiológica ocorrida a partir da segunda metade do século XX, com o envelhecimento populacional e o predomínio das doenças crônico-degenerativas, temas abordados em profundidade também no contexto da iniciativa Brasil Saúde Amanhã (Fundação Oswaldo Cruz, 2013), particularmente por Ouverney e Noronha (2013), vem impondo a necessidade de se repensar o modelo de organização do sistema de saúde.

Uma vez que a integralidade do acesso aos serviços passa a ser requisito essencial para responder as necessidades de saúde das populações, a identificação e superação das barreiras para o acesso e uso se tornam imprescindíveis. Jacobs e colaboradores (2012) fazem uma revisão cuidadosa dos esquemas analíticos de identificação, destacando as barreiras geográficas derivadas da localização e da capacidade da oferta e a distância, tempo e custo do transporte. 
A distância existente entre a residência dos pacientes e o local de atendimento, decorrente da grande dimensão territorial do país assinalada anteriormente (Unglert, Rosenburg \& Junqueira, 1987) vem sendo analisada por vários autores. Oliveira, Carvalho e Travassos (2004) fizeram um esforço pioneiro para mapear as redes reais de atenção que estavam sendo definidas pelo deslocamento das pessoas para o atendimento pelo SUS. Esse tipo de estudo permite a identificação de vazios assistenciais, contribuindo para a elaboração de estratégias de longo prazo para superação ou minimização dessas barreiras de acesso. O mesmo estudo revela a formação de redes distintas que variam com os diferentes níveis de complexidade dos recursos assistenciais. Em outro estudo, Oliveira e colaboradores (2011) ressaltaram a importância de identificar os polos de atendimento, as distâncias percorridas por pacientes para obter cuidado de saúde e o volume de pessoas envolvido nesses deslocamentos.

A teoria dos grafos é uma abordagem matemática para ordenar grupamentos de registros por localidade, magnitude e/ou direção de fluxos de pacientes. O primeiro grafo da história foi desenvolvido pelo matemático Leonhard Euler (1736) para solucionar o seguinte problema teórico como atravessar todas as pontes da cidade de Königsberg sem repetição de pontes. Euler tratou as pontes como arestas e suas intersecções como vértices, solucionando a questão (Diestel, 2005). A aplicação computacional da teoria dos grafos permite de forma mais facilitada criar e analisar mapas de fluxos de pacientes que relacionam o destino do atendimento (local) e a origem do paciente (residência), além de apontar possíveis polos e redes de atendimento em saúde.

Os objetivos desta pesquisa foram analisar o volume de internações hospitalares e de procedimentos diagnósticos e terapêuticos em pacientes não hospitalizados no SUS e estabelecer o fluxo desses pacientes no território nacional. As internações hospitalares foram classificadas em dois grupos de diferente complexidade: baixa-média (BMC) e alta (AC). Buscou-se estudar as diversas situações de concentração de internações e procedimentos nos municípios brasileiros, no período de 2010 a 2012 .

Para a análise dos fluxos, elaborou-se um grafo que considera os deslocamentos de pacientes dos municípios com menor frequência de procedimentos realizados para aqueles com maior frequência desses mesmos procedimentos. Com isso, observou-se a dominância do fluxo e o local de atração e concentração de pacientes evidenciando o polo de atendimento.

Na primeira parte é feita uma descrição do método empregado no estudo. Na segunda parte são apresentados os resultados das análises efetuadas, respectivamente, para o conjunto e para subgrupos de internações hospitalares e procedimentos diagnósticos e terapêuticos selecionados. Na última parte, são indicadas algumas conclusões do trabalho.

\section{Formação dos Fluxos e dos Grupos de Procedimentos}

Neste estudo utilizaram-se duas bases de dados: o Sistema de Informação Hospitalar (SIH) para as internações hospitalares do SUS e o Sistema de Informação Ambulatorial (SIA) para os procedimentos diagnósticos e terapêuticos selecionados. Essas bases são geridas pelo Ministério da Saúde, por intermédio da Secretaria de Assistência à Saúde, em conjunto com as secretarias estaduais municipais de saúde, sendo processadas pelo Departamento de Informática do SUS (Datasus), da Secretaria Executiva do Ministério da Saúde. As unidades hospitalares participantes do SUS (públicas 
ou privadas conveniadas) enviam as informações das internações efetuadas através do formulário Autorização de Internação Hospitalar (AIH) para os gestores municipais ou estaduais. Essas informações são processadas no Datasus, gerando os créditos referentes aos serviços prestados e formando uma base de dados bastante robusta, contendo dados de grande parte das internações hospitalares realizadas no Brasil.

Os registros de internações hospitalares e procedimentos diagnósticos e terapêuticos entre 2010 e 2012 do SIH foram utilizados na construção dos grupos de complexidade baixa-média, alta e grupos de serviços de apoio diagnóstico e terapêutico (SADT) (Quadro 1). As internações foram classificadas segundo especialidades médico-cirúrgicas, gênero e grupos etários específicos e agrupadas por grau de complexidade.

Para seleção dos registros e criação do fluxo de pacientes foram seguidas as etapas apresentadas no fluxograma da Figura 1.

Quadro 1 - Grupos de internações hospitalares e procedimentos diagnósticos e terapêuticos realizados pela rede de estabelecimentos de saúde

\section{I - Grupos de procedimentos para baixa-média} complexidade: internações

1) Pediatria - Internação clínica (0-15 anos)

2) Pediatria - Internação cirúrgica (0-15 anos)

3) Mulher - Internação ginecológica clínica ou cirúrgica (mulheres de 15 anos ou mais)

4) Mulher - Internação obstétrica para parto normal (mulheres de 15 a 49 anos)

5) Mulher - Internação obstétrica para parto cesariano (mulheres de 15 a 49 anos)

6) Mulher - Internação obstétrica para curetagem pós-aborto (mulheres de 15 a 49 anos)

7) Adulto - Internação clínica (todos, 15 a 64 anos)

8) Adulto - Internação cirúrgica de baixa e média complexidade (todos, 15 a 64 anos)

9) Idoso - Internação clínica (65 anos ou mais)

10) Idoso - Internação cirúrgica (65 anos ou mais)

11) Trauma - Internação clínica ou cirúrgica em todas as idades

II - Grupos de procedimentos diagnósticos e terapêuticos: SADT

12) SADT - Tomografia computadorizada

13) SADT - Ressonância magnética

14) SADT - Mamografia

15) SADT - Quimioterapia

16) SADT - Radioterapia
III - Grupos de procedimentos de AC

17) Angioplastia

18) Cirurgia de revascularização do miocárdio

20) Internação em UTI adulto

21) Internação em UTI pediátrica

22) Internação em UTI neonatal

23) Transplante de córnea

24) Transplante de rim

25) Transplante de demais órgãos sólidos

26) Transplante de medula óssea

27) Neurocirurgia

28) Cirurgia ortopédica do joelho

29) Cirurgia ortopédica do quadril

30) Cirurgia oncológica de útero e ovário

31) Cirurgia oncológica de mama

32) Cirurgia oncológica de próstata

33) Cirurgia oncológica de tireoide

34) Cirurgia oncológica de cólon e reto

35) Cirurgia oncológica de estômago 
Figura 1 - Esquema para seleção dos registros e criação dos fluxos de pacientes

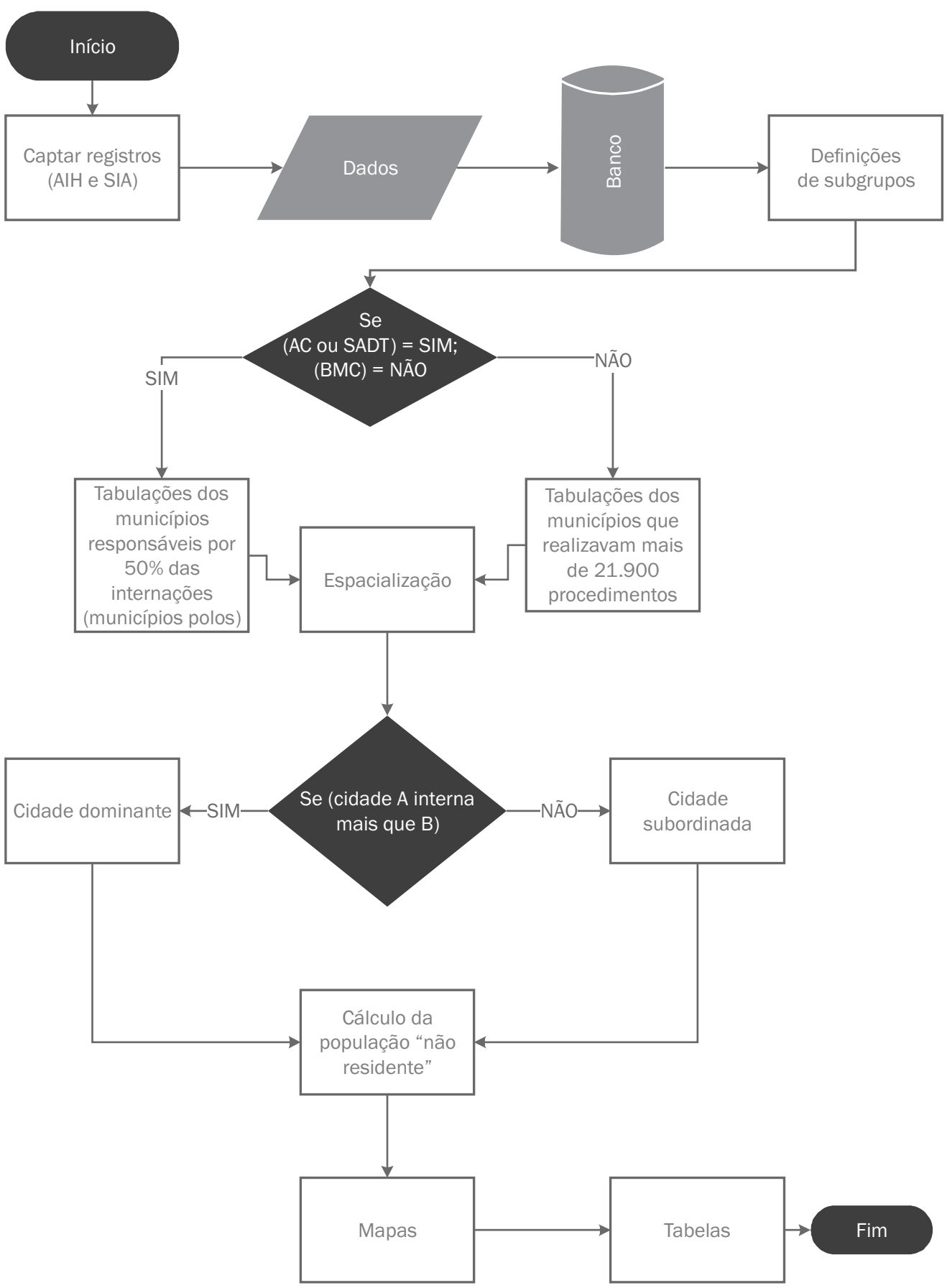

Fonte: adaptado de Diestel (2005). 
Os registros de internações e dos principais procedimentos diagnósticos e terapêuticos foram reunidos e gerenciados no Postgresql. ${ }^{1}$ Consideraram-se os dois grandes grupos de internações por classe de complexidade e o grupo de procedimentos diagnósticos e terapêuticos. Esses três grupos foram subdivididos em função de como se manifesta o volume de pacientes, por especialidade da internação e tipo de procedimento, levando-se em conta as situações de concentração em determinados municípios e as situações em que esse volume está disperso entre municípios.

Para a criação de subgrupos de internação hospitalar em cada classe de complexidade, utilizou-se como critério selecionar as especialidades de maior representatividade, com 50\% ou mais dos atendimentos. Um exemplo prático é o da composição do subgrupo de "pediatria - internação clínica", em que foram agregados procedimentos de:

- tratamento de pneumonias ou influenza (gripe);

- tratamento de doenças infecciosas e intestinais;

- tratamento das doenças crônicas de vias aéreas inferiores;

- tratamento de outros transtornos relacionados ao período perinatal;

- tratamento de transtornos relacionados com a duração da gestação e com o crescimento fetal.

Em seguida, quando a relação de procedimentos era muito diversificada foram selecionados apenas os vinte primeiros itens da "Tabela de Procedimentos do SUS" (2008).

Na primeira caixa de condição do fluxograma temos: se o grupo de procedimentos condiz com AC ou SADT é aplicada uma tabulação de número de municípios responsáveis por até $50 \%$ das internações de alta complexidade ou exames SADT. Quando a condição é negativa (grupo de procedimento BMC) os dados foram tabulados para municípios que realizaram no mínimo 21.900 (ocupação de 80\% dos leitos, média de quatro dias por internação, 7.300 por ano), considerando as internações no período.

$\mathrm{Na}$ fase seguinte, realizou-se o processo de espacialização dos dados tabulares. Assim, cada conjunto de registros recebe uma geometria para cada identidade espacial. Na segunda caixa de condição do fluxograma foi feita a classificação dos municípios polos pela condição, se a cidade B envia pacientes para cidade A, e B tem um volume de internação menor que A, então a cidade A é considerada dominante e a cidade B é considerada subordinada (Nystuen \& Dacey, 1961). Com base nas derivações da teoria de Euler, é possível construir um grafo chamado de orientado, no qual suas arestas apresentam uma direção definida. Num grafo orientado é possível ir do ponto A ao ponto B, entretanto, não é possível realizar o caminho inverso através da mesma aresta (Diestel, 2005). Dadas essas relações topológicas aplicadas na etapa de espacialização descrita no fluxograma, foi possível realizar uma análise de fluxos entre localidades, pois, uma linha une um par de pontos sempre que aceita a condição intitulada desigualdade triangular ou transitividade.

Segundo a teoria dos grafos, a rede de estrutura geográfica tem como suporte a abstração de um grafo $\mathrm{G}=[\mathrm{N}, \mathrm{A}, \phi]$, onde $\mathrm{N}$ é um conjunto de nós (municípios polarizadores da demanda de saúde), A é um conjunto de arcos (caminho do município de residência até municípios de atendimento), e $\phi(\mathrm{a})=(\mathrm{u}, \mathrm{v})$ é uma função de incidência que associa cada arco a $\in \mathrm{A}$ e a um par de nós $(\mathrm{u}, \mathrm{v}) \in \mathrm{N}$.

\footnotetext{
${ }^{1}$ PostgreSQL é um sistema gerenciador de banco de dados objeto relacional (SGBDOR), desenvolvido como projeto de código aberto.
} 
No caso geográfico, os nós podem estar associados a uma localização (x,y) do espaço para fins de referência (Bondy \& Murty, 1976).

Atualmente, técnicas de hierarquias de rede permitem identificar onde ocorrem as centralidades da rede e os nós principais. Isso condensa a base conceitual para avanço nas discussões dos processos sociais de indicadores de ordem espacial na estrutura regional. Oliveira, Carvalho e Travassos (2004) descrevem o processo de classificação topológica das redes considerando a estrutura determinada pelos fluxos dominantes, evidenciando a estrutura hierárquica da rede e ainda descrevendo relações internas e externas em cada rede.

Na AC exploraram-se 18 subgrupos, na BMC, 11 subgrupos e no SADT, cinco subgrupos. Sobre os procedimentos de SADT, optou-se por não agregar o número de procedimentos dentre todos os municípios já que a natureza diagnóstica e terapêutica varia desde procedimentos diagnósticos relativamente simples, como mamografias, a procedimentos terapêuticos com elevada complexidade, como radioterapia e quimioterapia.

A partir dos fluxos de deslocamento de pacientes, procedeu-se à seleção dos principais municípios que realizaram o maior volume de atendimentos segundo a frequência para cada grupo de complexidade analisada. No caso da alta complexidade, após um levantamento exploratório preliminar, decidiu-se analisar os vinte primeiros municípios que mais realizaram procedimentos. Esse ponto de corte contabiliza os municípios que realizaram $50 \%$ do total de procedimentos no país, com exceção de um subgrupo AC que contempla as cirurgias cardíacas valvulares de frequência irrisória. Esse mesmo ponto de corte foi aplicado nos procedimentos de SADT entre os quais apenas a mamografia foi uma exceção, já que nesse caso foram 68 municípios responsáveis por 50\% dos exames realizados no país.

Ao fim do fluxograma foram tabuladas as proporções de atendimentos de população não residente segundo frequência e fluxos dos pacientes não residentes, considerando como deslocamento de pacientes apenas o envio de indivíduos dos quais o município de origem apresenta volume de atendimentos menor que o ocorrido no município de destino.

Os mapas de fluxos procuram relacionar o destino e a origem do atendimento, além de indicar possíveis polos e redes de atendimento, segundo procedimentos analisados. O cálculo de fluxo foi elaborado de forma que fluxos eventuais, que são aqueles segundo os quais o paciente se desloca para um município com menor frequência (ou seja, pessoas que saem de grandes municípios para tratamento em pequenos municípios), não fossem computados. As legendas foram construídas segundo quartis e apresentadas em seis classes. Na elaboração das legendas, descartaram-se as classes com fluxos de valores muito baixos. Por conta disso, pode-se verificar que embora não sejam apresentadas as seis classes em alguns mapas, a distribuição seguiu a mesma metodologia para todos os mapas.

Os resultados são apresentados através de tabulação e mapeamento considerando a frequência de atendimentos nos municípios e o fluxo de pacientes não residentes para cada um dos subgrupos de complexidade. Foram elaborados dois tipos de mapas e tabelas para os 36 grupos de procedimentos. Um apresenta a distribuição segundo frequência de procedimentos realizados e outro apresenta os fluxos de atendimentos considerando o município de residência dos pacientes. 


\section{Resultados}

\section{Municípios responsáveis pela maior parte das internações hospitalares e procedimentos diagnósticos e terapêuticos}

A situação de concentração da atenção é diretamente proporcional à complexidade das internações e dos procedimentos. De modo geral, é possível classificar os fluxos de pacientes segundo os procedimentos analisados e as distâncias percorridas da seguinte forma: BMC - pequenas distâncias percorridas pelos pacientes e polos intraestaduais; SADT e AC - fluxos intensos dependendo da especialidade, e distâncias maiores, indicando polos nacionais.

Por meio de uma listagem de códigos atribuídos a cada grupo de procedimentos foi possível identificar os municípios responsáveis pela maior frequência de atendimentos para cada conjunto de procedimentos. Inicialmente, procurou-se identificar quais seriam os municípios que no conjunto atenderiam pelo menos 50\% da demanda nacional. Como se vê na Tabela 1, no caso dos procedimentos de alta complexidade, é extremamente baixo o número de municípios brasileiros que em conjunto realizam 50\% dos procedimentos. No caso dos SADT, a concentração do atendimento também é grande, excetuado o caso da mamografia.

Tabela 1 - Número de municípios que atenderam 50\% das internações e procedimentos diagnósticos e terapêuticos. Brasil - 2010 a 2012

\begin{tabular}{|c|c|}
\hline Procedimentos & $\mathrm{N}^{\circ}$ municípios \\
\hline \multicolumn{2}{|l|}{ Alta Complexidade } \\
\hline Angioplastia & 20 \\
\hline Cirurgia de revascularização do miocárdio & 12 \\
\hline Internação em UTI adulta & 36 \\
\hline Internação em UTI pediátrica & 14 \\
\hline Internação em UTI neonatal & 27 \\
\hline Transplante de córnea & 8 \\
\hline Transplante de rim & 5 \\
\hline Transplante de demais órgãos sólidos & 4 \\
\hline Transplante de medula óssea & 4 \\
\hline Neurocirurgia & 21 \\
\hline Cirurgia ortopédica do joelho & 21 \\
\hline Cirurgia ortopédica do quadril & 34 \\
\hline Cirurgia oncológica de útero e ovário & 12 \\
\hline Cirurgia oncológica de mama & 13 \\
\hline Cirurgia oncológica de próstata & 8 \\
\hline Cirurgia oncológica de tireoide & 8 \\
\hline Cirurgia oncológica de cólon e reto & 13 \\
\hline Cirurgia oncológica de estômago & 15 \\
\hline
\end{tabular}


Tabela 1 - Número de municípios que atenderam 50\% das internações e procedimentos diagnósticos e terapêuticos. Brasil - 2010 a 2012 (cont.)

\begin{tabular}{l|c|}
\hline \multicolumn{1}{|c|}{$\quad$ Procedimentos } & $N^{\circ}$ municípios \\
\hline SADT & \\
\hline Tomografia computadorizada & 26 \\
\hline Ressonância magnética & 17 \\
\hline Mamografia & 68 \\
\hline Quimioterapia & 19 \\
\hline Radioterapia & 19 \\
\hline Baixa-média complexidade & \\
\hline Pediatria - Internação clínica (0-15 anos) & $25^{*}$ \\
\hline Pediatria - Internação cirúrgica (0-15 anos) & $33^{*}$ \\
\hline Mulher - Internação ginecológica clínica (15 anos ou mais) & $129^{*}$ \\
\hline Mulher - Internação obstétrica para parto normal (15 a 49 anos) & $116^{*}$ \\
\hline Mulher - Internação obstétrica para parto cesariano (15 a 49 anos) & $101^{*}$ \\
\hline Mulher - Internação obstétrica para curetagem pós-aborto (15 a 49 anos) & $69^{*}$ \\
\hline Adulto - Internação clínica (15 a 64 anos) & $261^{*}$ \\
\hline Adulto - Internação cirúrgica BMC (15 a 64 anos) & $103^{*}$ \\
\hline Idoso - Internação clínica (65 anos ou mais) & $321^{*}$ \\
\hline Idoso - Internação cirúrgica (65 anos ou mais) & $63^{*}$ \\
\hline Trauma - Internação clínica ou cirúrgica em todas as idades & $56^{*}$ \\
\hline
\end{tabular}

*número de municípios responsáveis por mais de 21.900 atendimentos - unidade de saúde com cem leitos apresentando ocupação de $80 \%$ dos leitos e média de quatro dias por internação, o que significa cerca de 7.300 internações por ano.

\section{Municípios segundo tipos de procedimentos de alta complexidade atendidos}

Outra forma de caracterizar a importância dos municípios para o atendimento da demanda determinada pelas necessidades de saúde pode ser baseada na capacidade de atendimento para o conjunto de subgrupos ou parte deles em cada grupo de complexidade.

No Gráfico 1 são apresentados os municípios com a maior frequência de procedimentos de alta complexidade realizados, número de especialidades atendidas pelos municípios, proporção de atendimentos do município em relação ao total do país e a proporção acumulada. No país, trinta municípios são responsáveis por 50\% das internações de alta complexidade atendidas pelo sistema público de saúde. Dentre as especialidades não realizadas destacam-se o transplante de demais órgãos sólidos e o transplante de medula óssea, ambos os procedimentos realizados por apenas 25 municípios no país e com frequência de atendimento irrisória. 
Gráfico 1 - Municípios que responderam por 50\% dos atendimentos de alta complexidade e número de subgrupos nos quais aparecem como mais importantes. Brasil - 2010 a 2012

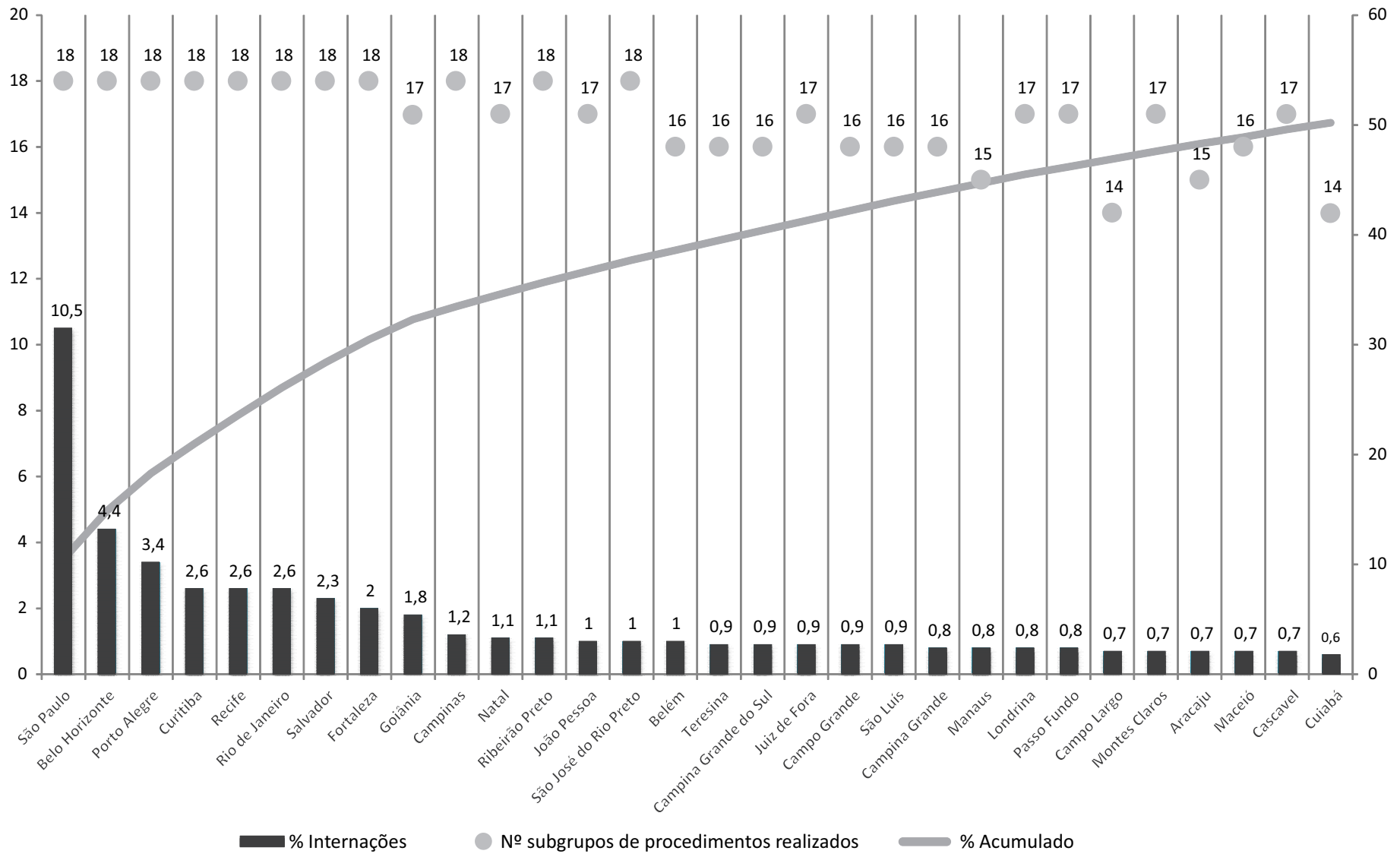

Fonte: Datasus.

Municípios mais desenvolvidos economicamente realizam todos os grupos de procedimentos, sobretudo com maior volume de procedimentos mais complexos. Nas listagens dos municípios também é possível observar que os municípios mais populosos se encontram sempre presentes. Embora as capitais constem em quase todas as listagens de municípios, verificam-se situações em que a população do município parece ser mais preponderante, o que é mais comum nos procedimentos de baixa complexidade. Nos níveis mais altos de complexidade, nos quais é maior o percentual de atendimento a não residentes, municípios das capitais se apresentam como polos mais importantes.

No Gráfico 2 são listados os trinta municípios com maior frequência de atendimentos de alta complexidade e é indicada a proporção de atendimentos realizados segundo residentes e não residentes no período de 2010 a 2012. Esses municípios respondem por 50\% dos atendimentos no país. O município de São Paulo foi o que mais realizou procedimentos de alta complexidade no período, cerca de 247 mil, correspondendo a 10\% do total de atendimentos no país. Entretanto, apenas 13\% desse volume decorre de pacientes oriundos de outros municípios. O município de Cuiabá foi o responsável pelo maior volume de atendidos não residentes no município, com cerca de $16 \%$, seguido de Porto Alegre, Recife, Campinas e Campina Grande do Sul com 15\% dos pacientes oriundos de outros 
municípios. Para todo o conjunto dos trinta municípios listados, a média de atendidos residentes em outros municípios foi de cerca de 10\%. Os municípios de Aracaju, Campina Grande, Fortaleza, São Luís e Manaus atenderam cerca de 1\% de pacientes não residentes.

Gráfico 2 - Municípios com as maiores frequências de internação de alta complexidade e proporção de não residentes atendidos. Brasil - 2010 a 2012

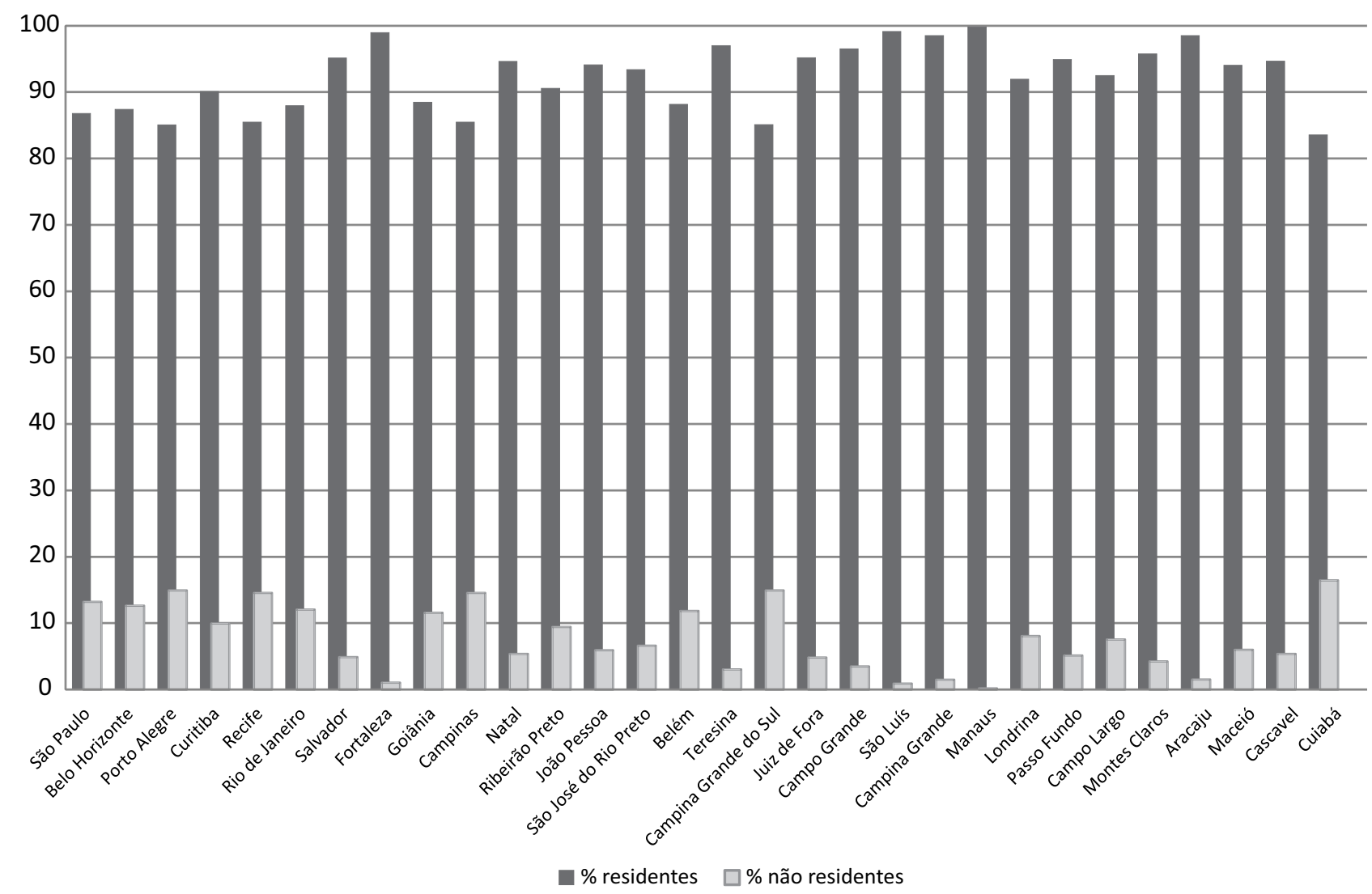

Fonte: SIH.

Na baixa-média complexidade notam-se semelhanças das redes de atenção quando se observam os mapas relativos a internações pediátricas clínicas e cirúrgicas, internações clínicas de adultos e internações para parto cesáreo. Nessas situações observa-se provavelmente a existência de leitos hospitalares de baixo grau de complexidade. No mesmo sentido, as cidades polos para as internações por procedimentos cirúrgicos em idosos, adultos e traumas parecem semelhantes.

Quando observados os principais municípios segundo frequência de atendimentos, destacam-se como polos: as capitais do Sudeste; no Nordeste, as cidades de Fortaleza, Recife e Salvador; no Sul, Porto Alegre e Curitiba; no Norte, Manaus; e no Centro-Oeste, Goiânia e Brasília. Esse comportamento pode ser atribuído ao número de habitantes residentes e dependentes de serviços nessas localidades. Mas também surgem nas análises alguns municípios como Ananindeua, São Gonçalo, Belford Roxo, Campinas, Ribeirão Preto e alguns outros municípios de regiões metropolitanas que se destacam pelo volume de internações. 
Os fluxos de internação para baixa-média complexidade geralmente descrevem pequenos trajetos percorridos para atendimento. Em procedimentos cirúrgicos os fluxos parecem ser mais intensos em comparação aos procedimentos clínicos. Observa-se isso claramente quando comparados os mapas de fluxo de internação para causas pediátricas clinicas e cirúrgicas. No caso dos partos, observam-se polos semelhantes de atendimentos, embora os partos cesarianos apresentem fluxos mais intensos, sobretudo na região Nordeste.

É importante analisar os procedimentos de SADT separadamente. No caso das mamografias, observa-se além de grandes capitais como São Paulo, Rio de Janeiro, Salvador, Recife, Fortaleza e Vitória, cidades de médio porte como Barretos, Joinville, Campinas, Guarulhos e São Bernardo do Campo que se destacam quanto ao maior volume de atendimentos.

No caso dos procedimentos de quimioterapia e radioterapia os polos de atendimento são muito semelhantes em sua distribuição espacial. Nesses procedimentos, as capitais do Nordeste, Sudeste e Sul do país sobressaem. Entretanto, destacam-se também cidades com referência para tratamento oncológico como Barretos, Cascavel, Jaú, Campina Grande do Sul, Sorocaba e Ribeirão Preto. Os mapas de fluxo para esses procedimentos revelam maiores distâncias percorridas, sobretudo porque pacientes do Norte e do Centro-Oeste do país buscam atendimento em municípios do Sul e Sudeste.

Os procedimentos de tomografia computadorizada e ressonância magnética contam com polos similares de atendimento. No entanto, os procedimentos de tomografia computadorizada parecem estar mais dispersos em vários municípios do território nacional, ao passo que a ressonância magnética indica estar mais concentrada em um número menor de municípios. Por conta disso, quando se observa o fluxo de pacientes, no caso das ressonâncias magnéticas, as distâncias percorridas são maiores, por outro lado nas tomografias os fluxos parecem ser mais regionais, com menores distâncias percorridas.

\section{Municípios segundo atenção a residentes e não residentes por grupos de procedimentos}

São listadas abaixo algumas das principais causas de internações no país na perspectiva de comportamento da demanda para o serviço de saúde e prognóstico de evolução dos quadros de oferta segundo projeções aceitáveis e pautadas no comportamento e composição etária de países desenvolvidos. Os procedimentos escolhidos também buscam uma aproximação com a oferta e o acesso a serviços de saúde centrados em grupos populacionais vulneráveis. Para isso são apresentados procedimentos de baixa-média e alta complexidade e serviços de apoio, diagnóstico e terapêutico.

\section{BMC: pediatria - internação clínica e cirúrgica}

Entre os procedimentos BMC é possível ilustrar, com base na análise de internações pediátricas, um quadro geral que se manifesta nos demais procedimentos com este nível de complexidade. Observa-se nesses procedimentos que a intensidade do fluxo é diretamente proporcional à complexidade do atendimento e os polos seguem uma hierarquia que respeita os limites administrativos das unidades da federação. Entretanto, polos de atendimento em áreas de fronteiras de estados e, sobretudo, quando apresentam centros de referências importantes, demonstram uma configuração 
que segue uma lógica que não respeita uma hierarquia administrativa de unidade federada para o fluxo de pacientes.

Na Tabela 2 estão listados os vinte municípios que mais realizaram internações cirúrgicas pediátricas tanto para residentes quanto para não residentes no período de 2010 a 2012 . Entre os que mais atenderam residentes, esse conjunto de municípios responde por $1 / 3$ do volume total de internações no país. Observa-se que o município de São Paulo atendeu 6\% dos pacientes, seguido de Recife, Salvador, Curitiba, Rio de Janeiro, Fortaleza e Belo Horizonte. Esses municípios concentram cerca de $20 \%$ dos atendimentos realizados no território nacional. Destaca-se que na tabela são listadas apenas capitais entre os municípios com maior número de internações para residentes, exceto a cidade de Paulista (PE), próxima a Olinda (PE).

Também se verificam na tabela os municípios que mais atenderam pacientes que tiveram que se deslocar do seu município de residência. Foram quase dois milhões de atendimentos cirúrgicos pediátricos ocorridos no período, desses, mais de 360 mil provenientes de pacientes que buscaram atendimento em outros municípios. Os vinte municípios que mais atenderam pacientes não residentes respondem por mais de $46 \%$ dos pacientes que tiveram que se deslocar. Somente o município de Recife recebeu cerca de 7\% desse total, seguido de Curitiba com cerca de 5\%, São Paulo, Belo Horizonte e Porto Alegre, em torno de 3\% dos atendimentos. Os municípios de Paulista (PE), Vitória de Santo Antão (BA), Campo Largo (PR), Diadema (SP), Vila Velha (ES) e Ribeirão Preto (SP) registram importante número de pacientes oriundos de outros municípios. Cerca de metade das internações pediátricas cirúrgicas que ocorreram em Recife foram de pacientes vindos de outros municípios. Essa situação é semelhante em alguns outros municípios de pequeno porte, entretanto, nas grandes capitais, entre um quarto e um sexto dos pacientes atendidos são oriundos de outros municípios.

Tabela 2 - Frequência e fluxo de pacientes de pediatria cirúrgica nos vinte municípios com maior número de atendimentos. Brasil - 2010 a 2012

\begin{tabular}{|l|c|c|c|}
\hline \multicolumn{1}{|c}{ Municípios } & $\begin{array}{c}\mathrm{N}^{\mathrm{o}} \mathrm{de} \\
\text { atendimentos }\end{array}$ & $\%$ & $\begin{array}{c}\% \\
\text { Acumulado }\end{array}$ \\
\hline São Paulo & 119.490 & 5,71 & 5,71 \\
\hline Recife & 57.276 & 2,74 & 8,44 \\
\hline Salvador & 49.489 & 2,36 & 10,81 \\
\hline Curitiba & 48.075 & 2,30 & 13,10 \\
\hline Rio de Janeiro & 47.994 & 2,29 & 15,39 \\
\hline Fortaleza & 43.227 & 2,06 & 17,46 \\
\hline Belo Horizonte & 37.399 & 1,79 & 19,25 \\
\hline Porto Alegre & 28.124 & 1,34 & 20,59 \\
\hline Belém & 28.023 & 1,34 & 21,93 \\
\hline São Luís & 24.939 & 1,19 & 23,12 \\
\hline
\end{tabular}

\begin{tabular}{|l|r|c|c|}
\hline \multicolumn{1}{|c|}{ Municípios } & $\begin{array}{c}N^{\circ} \text { não } \\
\text { residentes }\end{array}$ & $\%$ & $\begin{array}{c}\% \\
\text { Acumulado }\end{array}$ \\
\hline Recife & 25113 & 6,90 & 6,90 \\
\hline Curitiba & 17330 & 4,76 & 11,66 \\
\hline São Paulo & 13318 & 3,66 & 15,32 \\
\hline Belo Horizonte & 11861 & 3,26 & 18,58 \\
\hline Porto Alegre & 11541 & 3,17 & 21,75 \\
\hline Rio de Janeiro & 10169 & 2,79 & 24,54 \\
\hline Salvador & 9541 & 2,62 & 27,17 \\
\hline Vitória & 8455 & 2,32 & 29,49 \\
\hline Fortaleza & 7238 & 1,99 & 31,48 \\
\hline Goiânia & 6901 & 1,90 & 33,37 \\
\hline
\end{tabular}


Tabela 2 - Frequência e fluxo de pacientes de pediatria cirúrgica nos vinte municípios com maior número de atendimentos. Brasil - 2010 a 2012 (cont.)

\begin{tabular}{|c|c|c|c|c|c|c|c|}
\hline Municípios & $\begin{array}{c}\mathrm{N}^{\mathrm{o}} \mathrm{de} \\
\text { atendimentos }\end{array}$ & $\%$ & $\begin{array}{c}\% \\
\text { Acumulado }\end{array}$ & Municípios & $\begin{array}{l}\mathrm{N}^{\mathrm{o}} \text { não } \\
\text { residente }\end{array}$ & $\%$ & $\begin{array}{c}\% \\
\text { Acumulado }\end{array}$ \\
\hline Manaus & 24.234 & 1,16 & 24,28 & São Luís & 6147 & 1,69 & 35,06 \\
\hline Maceió & 22.283 & 1,06 & 25,34 & Belém & 5836 & 1,60 & 36,67 \\
\hline Goiânia & 21.913 & 1,05 & 26,39 & Natal & 5650 & 1,55 & 38,22 \\
\hline Natal & 18.651 & 0,89 & 27,28 & Paulista & 5019 & 1,38 & 39,60 \\
\hline Teresina & 17.583 & 0,84 & 28,12 & $\begin{array}{l}\text { Vitória de Santo } \\
\text { Antão }\end{array}$ & 4862 & 1,34 & 40,93 \\
\hline João Pessoa & 16.187 & 0,77 & 28,89 & Campo Largo & 4620 & 1,27 & 42,20 \\
\hline Ribeirão Preto & 15.610 & 0,75 & 29,64 & Teresina & 4120 & 1,13 & 43,33 \\
\hline Brasília & 15.022 & 0,72 & 30,35 & Diadema & 4022 & 1,11 & 44,44 \\
\hline Aracaju & 13.991 & 0,67 & 31,02 & Vila Velha & 3951 & 1,09 & 45,52 \\
\hline Paulista & 13.859 & 0,66 & 31,68 & Ribeirão Preto & 3838 & 1,05 & 46,58 \\
\hline
\end{tabular}

Fonte: SIH

Na Figura 2 apresenta-se a comparação da distribuição gráfica do fluxo de internações clínicas pediátricas segundo o município de atendimento no período de 2010 a 2012 . Observa-se que nas internações pediátricas clínicas nas regiões Norte, Centro-Oeste e interior do Nordeste do país as capitais estaduais polarizam o fluxo de pacientes. Nas regiões Sudeste, Sul e região litorânea do Nordeste são observados municípios de médio porte que polarizam municípios vizinhos menores, determinando uma distribuição da rede de forma mais homogênea, e consequentemente distâncias mais curtas a percorrer dentro de uma mesma unidade federativa. No Nordeste, destacam-se as cidades de Recife, Fortaleza e São Luís como polos importantes de internação para municípios do interior dos estados.

No caso das internações cirúrgicas, de modo geral, os estados demonstram uma convergência dos fluxos de pacientes para as capitais e para cidades de médio porte dentro do limite da unidade federada. No entanto, observam-se fluxos mais intensos e deslocamentos maiores que o das internações clínicas. A lógica de regionalização já demonstra distorção em áreas limítrofes de estados e a resolutividade local não parece mais tão evidente quanto no caso das internações clínicas. Destaca-se o fluxo de pacientes do oeste do Paraná para a capital Curitiba, e do interior de Pernambuco, norte da Bahia e Paraíba para Recife. No sul do país parece ocorrer fluxo de pacientes do extremo sul do estado para Porto Alegre. Alguns estados como Bahia, São Paulo e Minas Gerais apresentam fluxos em que a polaridade da capital estadual não é tão notória, conformando regiões de deslocamento diferenciadas dentro da unidade federada e, consequentemente, mais polos de referência. 
Figura 2 - Fluxo de pacientes de pediatria cirúrgica e clínica por municípios, para atendimento no país no período de 2010 a 2012

FLUXO DE ATENDIMENTOS PARA

"PEDIATRIA - INTERNAÇÃO CIRÚRGICA" EM MENORES DE 15 ANOS NO TRIÊNIO 2010-2012

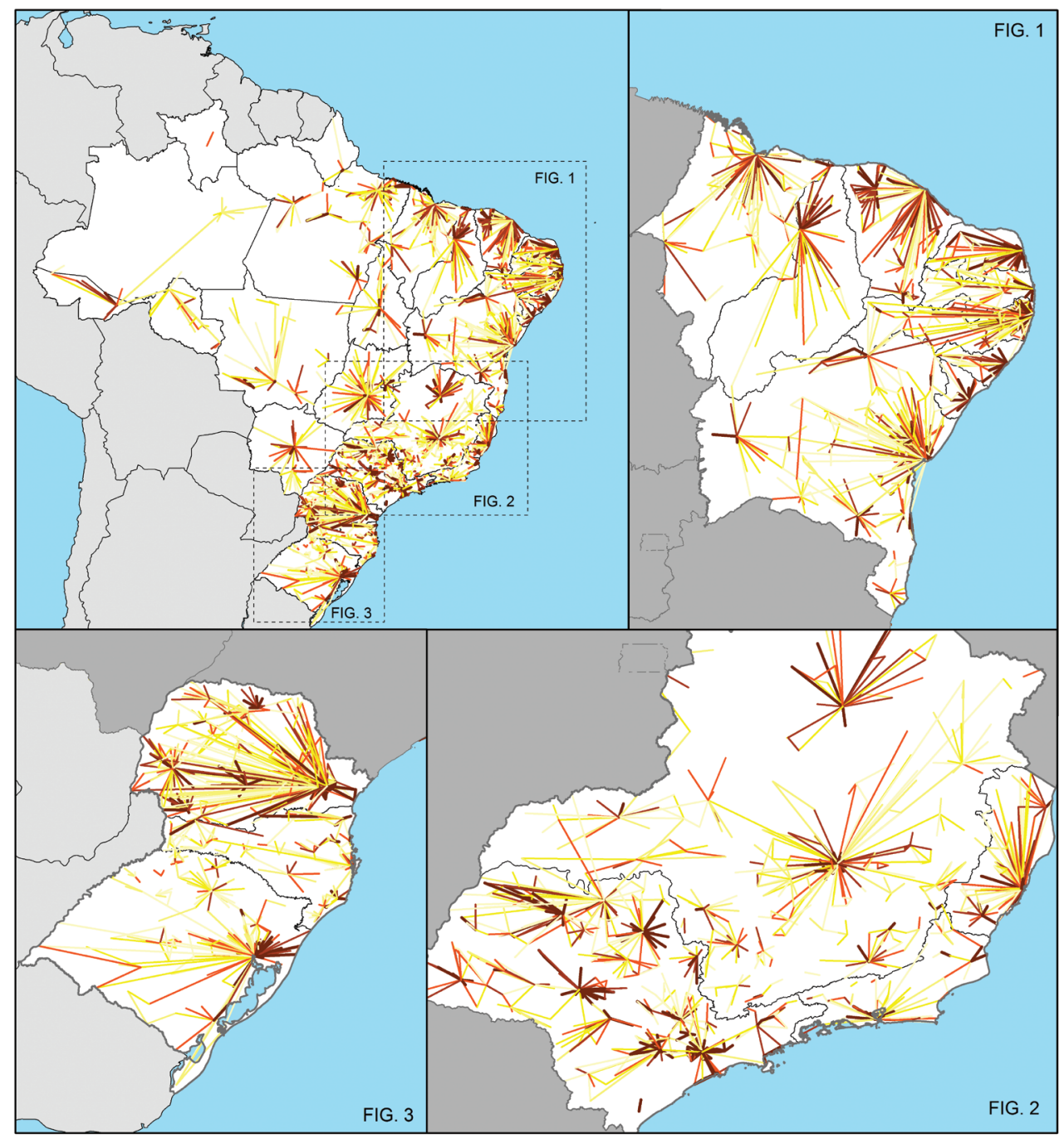

Legenda

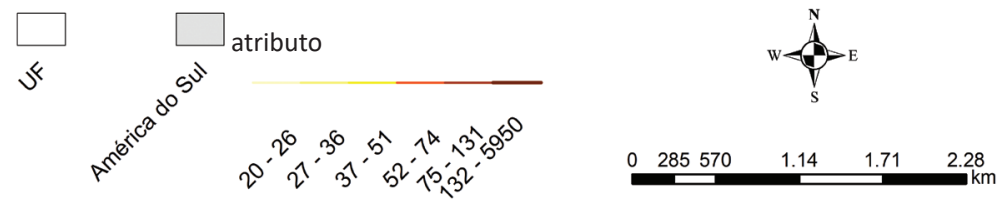


Figura 2 - Fluxo de pacientes de pediatria cirúrgica e clínica por municípios, para atendimento no país no período de 2010 a 2012 (cont.)

FLUXO DE ATENDIMENTOS PARA

"PEDIATRIA - INTERNAÇÃO CLÍNICA" EM MENORES DE 15 ANOS NO TRIÊNIO 2010-2012

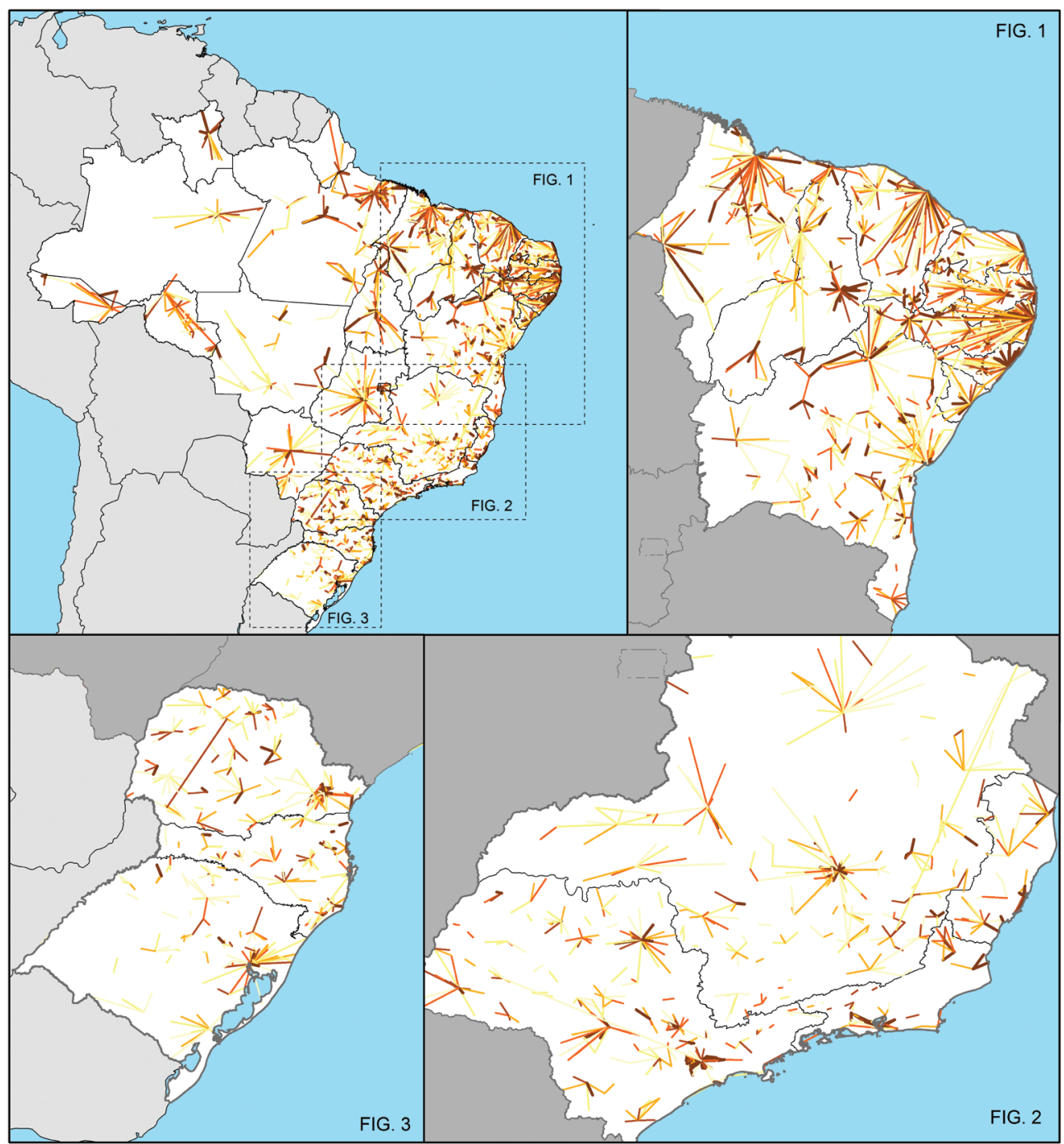

Legenda
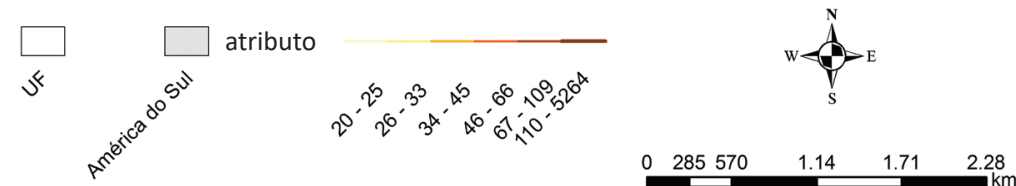
No Brasil, as principais causas de internação pediátrica clínica foram as pneumonias e as doenças intestinais, que juntas responderam por mais de um milhão e meio de internações no período. No caso das internações pediátricas cirúrgicas os principais procedimentos realizados foram amigdalectomia com adenoidectomia, postectomia e apendicectomia, correspondendo a pouco mais de 250 mil procedimentos. Com relação às internações cirúrgicas, as principais causas de internações são cirurgias que não demandam centros cirúrgicos complexos, e poderiam ser realizadas no município de residência, se este contasse com um mínimo de estrutura capaz de realizar o procedimento.

\section{BMC: trauma - internação clínica ou cirúrgica}

Os traumatismos, principalmente cranioencefálicos e os politraumatizados, estão diretamente relacionados aos acidentes de trânsito, agressões físicas, quedas e lesões por arma de fogo. Na Tabela 3 estão listados os vinte municípios que mais realizaram internações clínicas ou cirúrgicas BMC para traumas (excluídos procedimentos mal definidos, não especificados, diagnósticos, placas ou pinos) no período de 2010 a 2012. Esses municípios respondem por mais de 33\% do volume total de internações no país. Observa-se que o município de São Paulo atendeu cerca de 6,5\% dos pacientes, seguido de Recife, Belo Horizonte, Salvador, Fortaleza, Goiânia e Curitiba. Tais municípios concentram cerca de $20 \%$ dos atendimentos realizados no território nacional. Além das capitais, destacam-se os municípios de Paulista (PE), Ribeirão Preto e Bauru, ambos no estado de São Paulo. Cerca de 26\% dos procedimentos foram realizados em pacientes tratados fora do município de residência. Os vinte municípios do país que mais receberam pacientes de outros municípios respondem por cerca de 41\% dos pacientes que tiveram que se deslocar em busca de atendimento. Os municípios de Recife, Belo Horizonte, Goiânia, Salvador e São Paulo somam cerca de $20 \%$ desse total. No município de Recife mais de 50\% dos atendimentos para internação clínica e cirúrgica por trauma são decorrentes de pacientes não residentes no município, em Belo Horizonte 41\%, em Goiânia 45\% e em São Paulo 12\%.

Tabela 3 - Frequência e fluxo de pacientes de traumatologia segundo os vinte municípios com maior número de atendimento no país no período de 2010 a 2012

\begin{tabular}{|l|c|c|c|}
\hline \multicolumn{1}{|c|}{ Municípios } & $\begin{array}{c}\text { No de } \\
\text { atendimentos }\end{array}$ & $\%$ & $\begin{array}{c}\% \\
\text { Acumulado }\end{array}$ \\
\hline São Paulo & 128.348 & 6,5 & 6,5 \\
\hline Recife & 58.649 & 3,0 & 9,4 \\
\hline Belo Horizonte & 49.818 & 2,5 & 11,9 \\
\hline Salvador & 47.383 & 2,4 & 14,3 \\
\hline Fortaleza & 44.068 & 2,2 & 16,5 \\
\hline Goiânia & 43.775 & 2,2 & 18,7 \\
\hline Curitiba & 42.079 & 2,1 & 20,9 \\
\hline Rio de Janeiro & 36.194 & 1,8 & 22,7 \\
\hline Belém & 24.279 & 1,2 & 23,9 \\
\hline Porto Alegre & 22.479 & 1,1 & 25,0 \\
\hline Natal & 22.080 & 1,1 & 26,1 \\
\hline
\end{tabular}

\begin{tabular}{|l|c|c|c|}
\hline \multicolumn{1}{|c|}{ Municípios } & $\begin{array}{c}\mathrm{N}^{\mathrm{o}} \text { não } \\
\text { residentes }\end{array}$ & $\%$ & $\begin{array}{c}\% \\
\text { Acumulado }\end{array}$ \\
\hline Recife & 29.349 & 5,5 & 5,5 \\
\hline Belo Horizonte & 20.632 & 3,9 & 9,4 \\
\hline Goiânia & 19.957 & 3,8 & 13,2 \\
\hline Salvador & 17.857 & 3,4 & 16,6 \\
\hline São Paulo & 15.991 & 3,0 & 19,6 \\
\hline Curitiba & 13.619 & 2,6 & 22,2 \\
\hline Fortaleza & 13.492 & 2,5 & 24,7 \\
\hline Belém & 9.686 & 1,8 & 26,6 \\
\hline Porto Alegre & 8.806 & 1,7 & 28,2 \\
\hline Vitória & 8.366 & 1,6 & 29,8 \\
\hline Teresina & 7.661 & 1,4 & 31,3 \\
\hline
\end{tabular}


Tabela 3 - Frequência e fluxo de pacientes de traumatologia segundo os vinte municípios com maior número de atendimento no país no período de 2010 a 2012 (cont.)

\begin{tabular}{|c|c|c|c|c|c|c|c|}
\hline Municípios & $\begin{array}{c}\mathrm{N}^{\mathrm{o}} \text { de } \\
\text { atendimentos }\end{array}$ & $\%$ & $\begin{array}{c}\% \\
\text { Acumulado }\end{array}$ & Municípios & $\begin{array}{l}\mathrm{N}^{\mathrm{O}} \text { não } \\
\text { residentes }\end{array}$ & $\%$ & $\begin{array}{c}\% \\
\text { Acumulado }\end{array}$ \\
\hline Teresina & 20.624 & 1,0 & 27,2 & Natal & 7.504 & 1,4 & 32,7 \\
\hline Campo Grande & 18.412 & 0,9 & 28,1 & Bauru & 7.450 & 1,4 & 34,1 \\
\hline Ribeirão Preto & 17.867 & 0,9 & 29,0 & Barbalha & 6.983 & 1,3 & 35,4 \\
\hline Paulista & 17.027 & 0,9 & 29,9 & Paulista & 6.123 & 1,2 & 36,6 \\
\hline Manaus & 16.046 & 0,8 & 30,7 & Rio de Janeiro & 5.693 & 1,1 & 37,6 \\
\hline João Pessoa & 14.284 & 0,7 & 31,4 & Ananindeua & 5.499 & 1,0 & 38,7 \\
\hline Bauru & 14.208 & 0,7 & 32,1 & Ribeirão Preto & 5.461 & 1,0 & 39,7 \\
\hline São Luís & 13.746 & 0,7 & 32,8 & João Pessoa & 5.122 & 1,0 & 40,7 \\
\hline Vitória & 13.306 & 0,7 & 33,5 & $\begin{array}{l}\text { Mogi das } \\
\text { Cruzes }\end{array}$ & 4.872 & 0,9 & 41,6 \\
\hline
\end{tabular}

Obs: não incluídos procedimentos mal definidos, não especificados, diagnósticos, e retiradas de placas ou pinos. Fonte: SIH

Na Figura 3 verifica-se a distribuição gráfica do número de internações clínicas ou cirúrgicas para traumas segundo o município de atendimento e fluxo de deslocamento do paciente no período de 2010 a 2012. Os quadrados proporcionais em vermelho destacam os municípios citados na tabela anterior e que apresentam a maior frequência de internações. Nos círculos proporcionais em amarelo, os demais municípios que tiveram internação clínica ou cirúrgica por trauma no período. Observa-se que na região Sudeste, Sul e litoral do Nordeste a frequência das internações está distribuída de forma mais concentrada nas capitais e em cidades de médio porte, principalmente, no norte do Paraná, São Paulo, Rio Grande do Sul, sul de Minas Gerais, leste de Santa Catarina e litoral nordestino. As regiões Centro-Oeste, Norte e interior do Nordeste têm maior volume de internações somente nas capitais estaduais.

Na distribuição gráfica do fluxo de internações clínicas e cirúrgicas por traumas, segundo o município de atendimento, observa-se que, além das capitais, outros municípios dentro das unidades federadas polarizam os atendimentos. Os fluxos nos municípios do Nordeste e de São Paulo apresentam distribuição espacial similar à encontrada nas internações cirúrgicas em adultos. No estado de Minas Gerais e Sul do país observam-se fluxos menores, bem como no Centro-Oeste e Norte do país. 
Figura 3 - Frequência e fluxo de pacientes atendidos por trauma segundo municípios, 2010 a 2012

TOTAL DE ATENDIMENTOS PARA

"TRAUMA - INTERNAÇÃO CLÍNICA OU CIRÚRGICA" EM TODAS AS IDADES NO TRIÊNIO 2010-2012

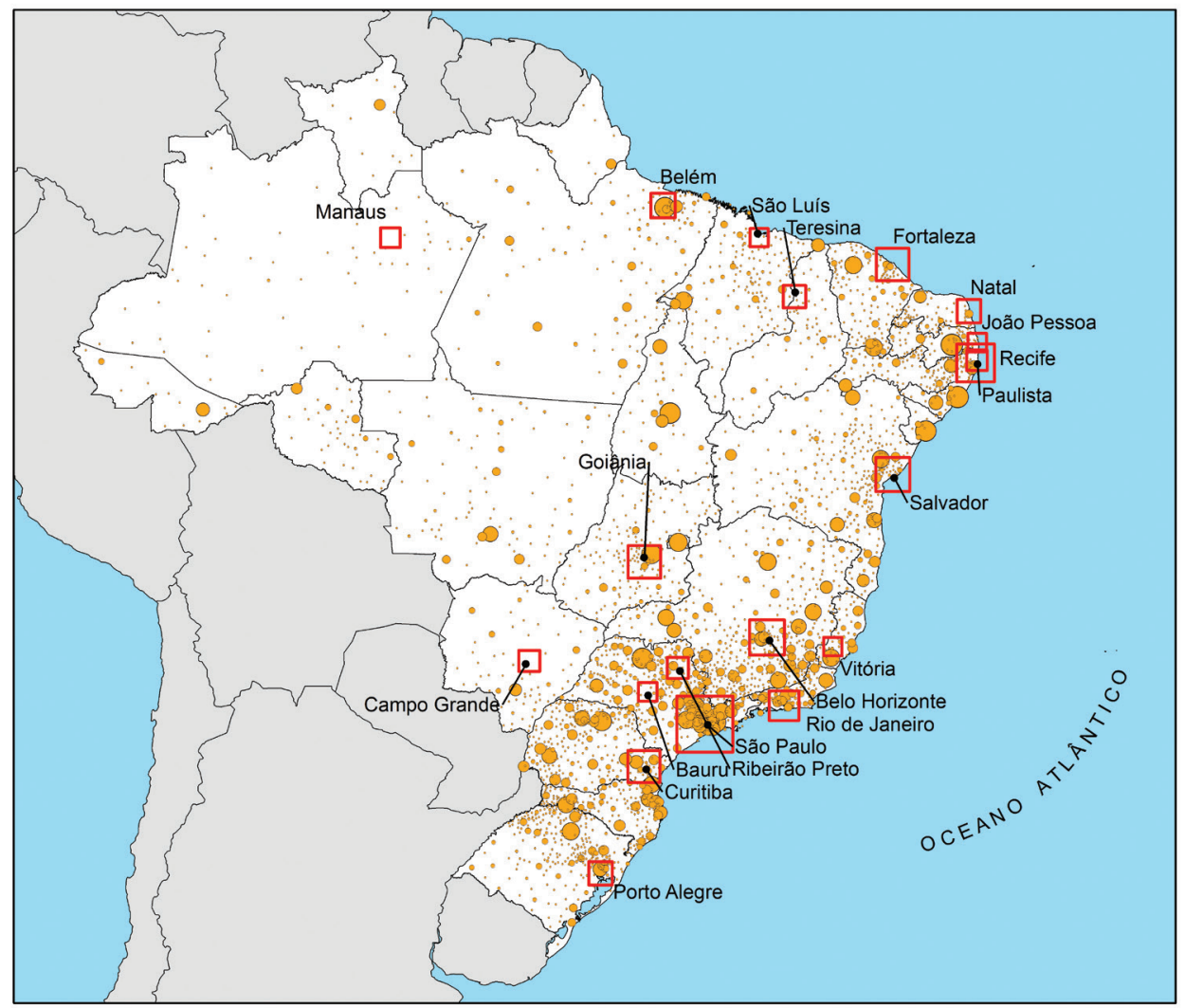

Legenda

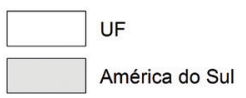

Símbolos proporcionais a frequência de internações

O $\quad 13.000$

- 6.500

- 3.250

20 municípios com maior número de internações

130.000

65.000

ㅁ 32.500

$\begin{array}{llll}220440 & 880 & 1.32 & 1.76\end{array}$

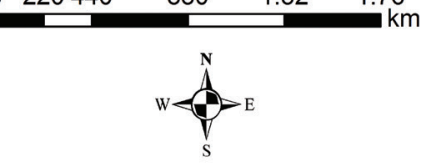


Figura 3 - Frequência e fluxo de pacientes atendidos por trauma segundo municípios, 2010 a 2012 (cont.)

FLUXO DE ATENDIMENTOS PARA

"TRAUMA - INTERNAÇÃO CLÍNICA OU CIRÚRGICA" EM TODAS AS IDADES NO TRIÊNIO 2010-2012

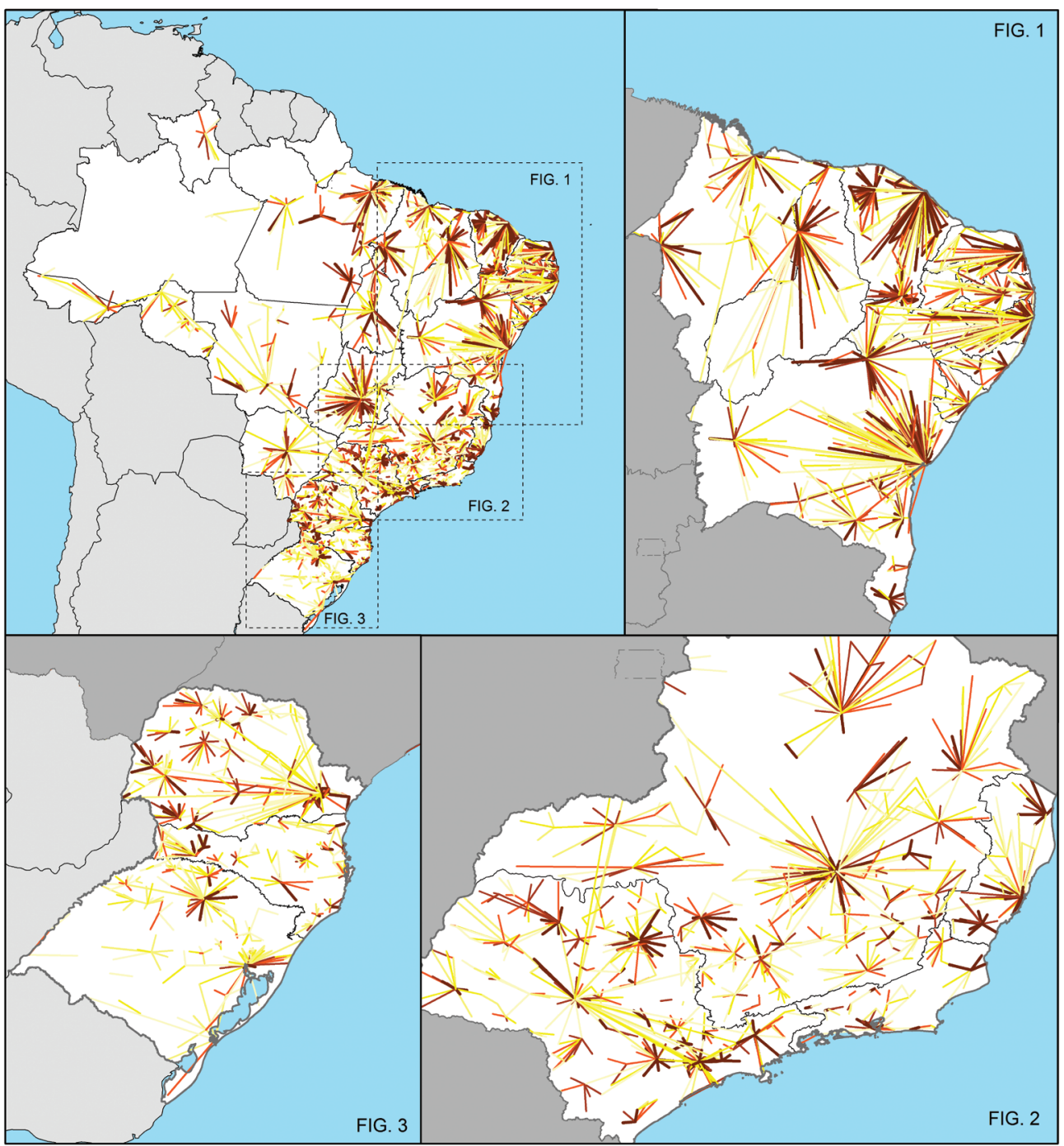

Legenda
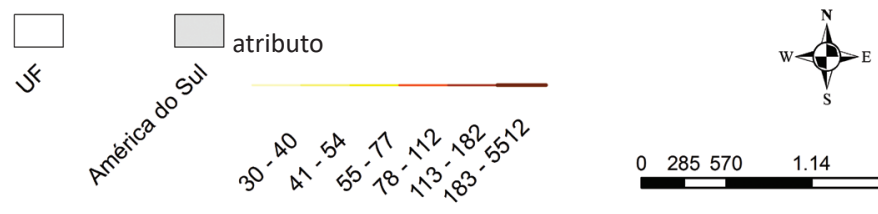

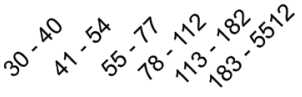

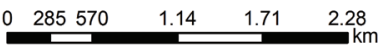




\section{SADT: mamografia}

O câncer de mama é a principal causa de morte por neoplasias entre mulheres adultas no país, e o risco de óbito aumenta à medida que as mulheres envelhecem (Lima-Costa, Peixoto \& Giatti, 2004). A mamografia é o método de monitoramento e rastreamento precoce mais eficaz para detecção do câncer de mama.

Na Tabela 4 estão listados os vinte municípios que mais realizaram procedimentos de mamografia no Brasil no período de 2010 a 2012. Esses municípios respondem por mais de 30\% do volume total de procedimentos realizados no país, que foi de 10.376.727. Observa-se que o município de São Paulo atendeu quase $8 \%$ dos pacientes, seguido de Salvador, Curitiba e Belo Horizonte. Tais municípios concentram cerca de $15 \%$ dos atendimentos realizados no território nacional. Além das capitais, destacam-se os municípios de Barretos (SP), Cascavel (PR), Guarulhos (SP), Campinas (SP), Joinville (SC) e São Bernardo do Campo (SP).

Mamografias realizadas fora do município de residência totalizam cerca de $4 \%$ em relação ao total. Na Tabela 4 também listam-se os vinte municípios do país que mais receberam pacientes de outros municípios e que correspondem a cerca de 60\% dos pacientes que tiveram de se deslocar em busca de atendimento. Os pacientes atendidos em Barretos (SP) totalizam cerca de 13\% dos pacientes atendidos fora do município de residência, e em adição aos atendidos em Recife, Salvador e São Paulo, agregam mais de $30 \%$ dos pacientes que realizaram o procedimento fora do município de residência. No total, cerca de 39\% dos atendidos em Barretos (SP) eram residentes de outros municípios; em Recife eram 19\% e em Salvador, 7\%.

Tabela 4 - Frequência de mamografias realizadas nos vinte principais municípios em residentes e não residentes. Brasil - 2010 a 2012

\begin{tabular}{|l|c|c|c|}
\hline \multicolumn{1}{|c}{ Municípios } & $\begin{array}{c}\mathrm{N}^{\mathrm{o}} \mathrm{de} \\
\text { atendimentos }\end{array}$ & $\%$ & $\begin{array}{c}\% \\
\text { Acumulado }\end{array}$ \\
\hline São Paulo & 818.055 & 7,9 & 7,9 \\
\hline Salvador & 344.878 & 3,3 & 11,2 \\
\hline Curitiba & 204.629 & 2,0 & 13,2 \\
\hline Belo Horizonte & 164.094 & 1,6 & 14,8 \\
\hline Porto Alegre & 157.632 & 1,5 & 16,3 \\
\hline Recife & 132.767 & 1,3 & 17,6 \\
\hline Barretos & 129.439 & 1,2 & 18,8 \\
\hline Rio de Janeiro & 124.907 & 1,2 & 20,0 \\
\hline Fortaleza & 115.436 & 1,1 & 21,1 \\
\hline Goiânia & 111.378 & 1,1 & 22,2 \\
\hline Manaus & 110.333 & 1,1 & 23,3 \\
\hline Maceió & 106.534 & 1,0 & 24,3 \\
\hline Cascavel & 88.831 & 0,9 & 25,1 \\
\hline Guarulhos & 88.490 & 0,9 & 26,0 \\
\hline
\end{tabular}

\begin{tabular}{|l|r|r|c|}
\hline \multicolumn{1}{|c}{ Municípios } & $\begin{array}{c}\text { No Não } \\
\text { residentes }\end{array}$ & \multicolumn{1}{c}{$\%$} & $\begin{array}{c}\% \\
\text { Acumulado }\end{array}$ \\
\hline Barretos & 51.705 & 13,85 & 13,85 \\
\hline Recife & 25.623 & 6,86 & 20,72 \\
\hline Salvador & 25.188 & 6,75 & 27,46 \\
\hline São Paulo & 16.235 & 4,35 & 31,81 \\
\hline Porto Alegre & 15.904 & 4,26 & 36,07 \\
\hline Pinhais & 12.097 & 3,24 & 39,31 \\
\hline Vitória & 11.138 & 2,98 & 42,30 \\
\hline Taboão da Serra & 7.407 & 1,98 & 44,28 \\
\hline Santos & 6.877 & 1,84 & 46,12 \\
\hline Sorocaba & 6.500 & 1,74 & 47,87 \\
\hline Giruá & 6.402 & 1,72 & 49,58 \\
\hline Curitiba & 6.223 & 1,67 & 51,25 \\
\hline Itapevi & 5.433 & 1,46 & 52,70 \\
\hline Campinas & 5.015 & 1,34 & 54,05 \\
\hline
\end{tabular}


Tabela 4 - Frequência de mamografias realizadas nos vinte principais municípios em residentes e não residentes. Brasil - 2010 a 2012 (cont.)

\begin{tabular}{|c|c|c|c|c|c|c|c|}
\hline Municípios & $\begin{array}{c}\mathrm{N}^{\mathrm{o}} \mathrm{de} \\
\text { atendimentos }\end{array}$ & $\%$ & $\begin{array}{c}\% \\
\text { Acumulado }\end{array}$ & Municípios & $\begin{array}{l}\mathrm{N}^{\mathrm{o}} \text { Não } \\
\text { residentes }\end{array}$ & $\%$ & $\begin{array}{c}\% \\
\text { Acumulado }\end{array}$ \\
\hline Vitória & 85.912 & 0,8 & 26,8 & $\begin{array}{l}\text { São João de } \\
\text { Meriti }\end{array}$ & 4.702 & 1,26 & 55,31 \\
\hline Sorocaba & 85.205 & 0,8 & 27,6 & Salto Grande & 4.615 & 1,24 & 56,54 \\
\hline Campinas & 82.002 & 0,8 & 28,4 & Cascavel & 3.999 & 1,07 & 57,61 \\
\hline Natal & 76.418 & 0,7 & 29,2 & $\begin{array}{l}\text { Conselheiro } \\
\text { Lafaiete }\end{array}$ & 3.728 & 1,00 & 58,61 \\
\hline Joinville & 73.757 & 0,7 & 29,9 & Jundiaí & 3.652 & 0,98 & 59,59 \\
\hline $\begin{array}{l}\text { São Bernardo } \\
\text { do Campo }\end{array}$ & 73.715 & 0,7 & 30,6 & Sapiranga & 3.636 & 0,97 & 60,57 \\
\hline
\end{tabular}

Na Figura 4 percebe-se a distribuição gráfica do número de procedimentos de mamografias realizadas segundo o município de atendimento no período de 2010 a 2012. Os quadrados proporcionais em vermelho destacam os municípios citados na tabela anterior e que apresentam a maior frequência de mamografias realizadas. Os círculos proporcionais em amarelo indicam os demais municípios que realizaram o procedimento. Observa-se concentração na frequência de procedimentos nos municípios das regiões Sul e Sudeste, principalmente, no leste do estado do Paraná, norte do estado de São Paulo, Rio de Janeiro e sul de Minas Gerais. A região litorânea do Nordeste e a cidade de Manaus, no Norte do país, também apresentaram elevado número de procedimentos realizados.

Quanto à distribuição gráfica do fluxo dos atendimentos de mamografias, observa-se que os fluxos mais intensos se deslocam do interior do estado da Bahia para a capital do estado. Outro polo importante, mas com menor volume de deslocamentos é observado no norte do estado de São Paulo, que recebe pacientes das regiões Norte, Nordeste e Centro-Oeste. Os demais fluxos têm comportamento regional, com poucas distâncias percorridas e pequeno volume de pacientes. 
Figura 4 - Frequência e fluxo de pacientes para realização de mamografias por municípios. Brasil 2010 a 2012
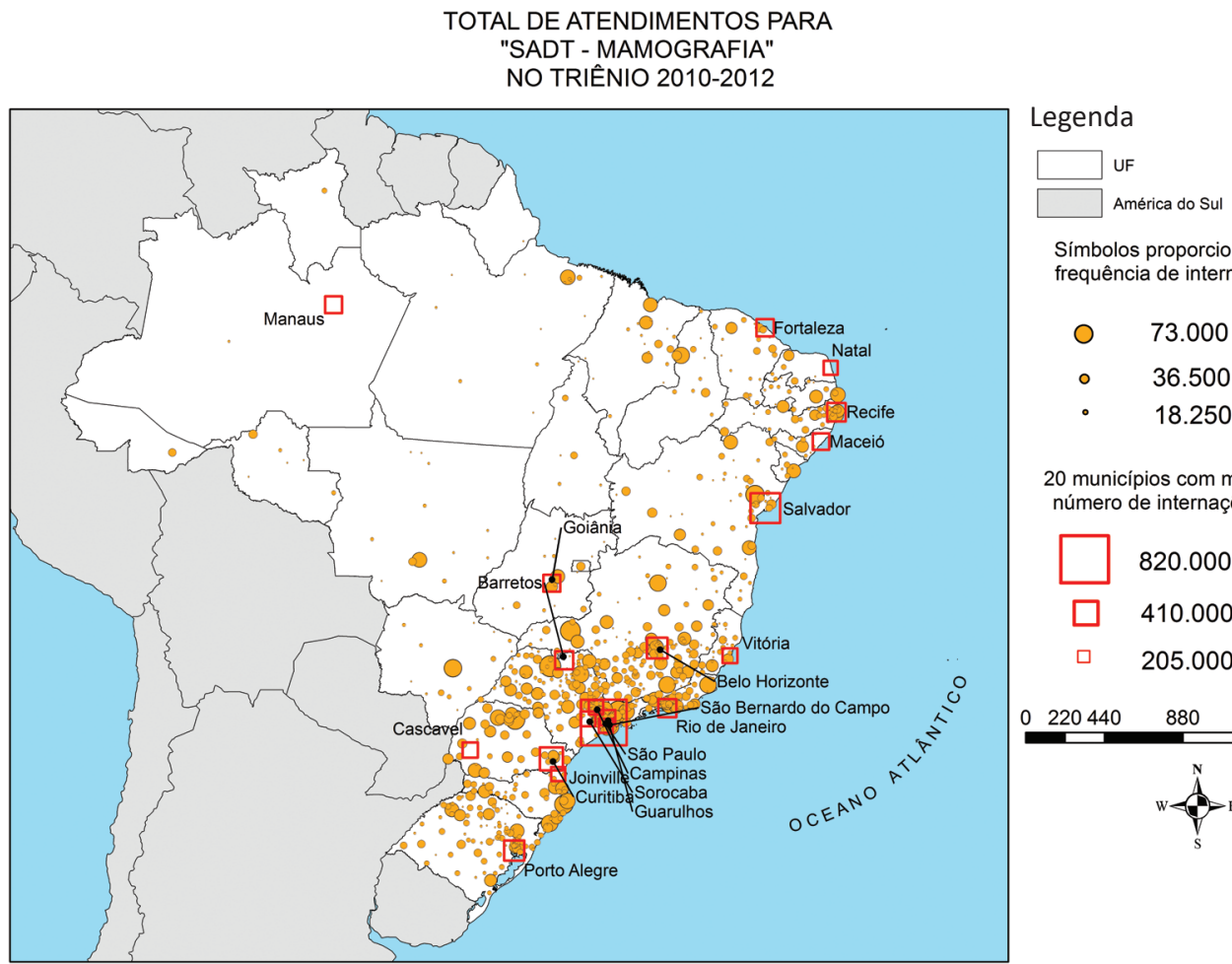

$$
\begin{array}{cc}
\begin{array}{c}
\text { Simbolos proporcionais a } \\
\text { frequência de internações }
\end{array} \\
\text { ○ } & 73.000 \\
\circ & 36.500 \\
\text { - } & 18.250
\end{array}
$$

20 municípios com maior número de internações
$\square$
820.000
$\square \quad 410.000$
205.000

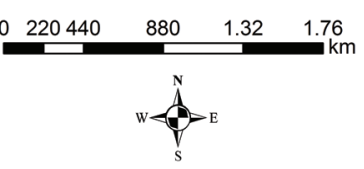

FLUXO DE ATENDIMENTOS PARA "SADT - MAMOGRAFIA" NO TRIÊNIO 2010-2012

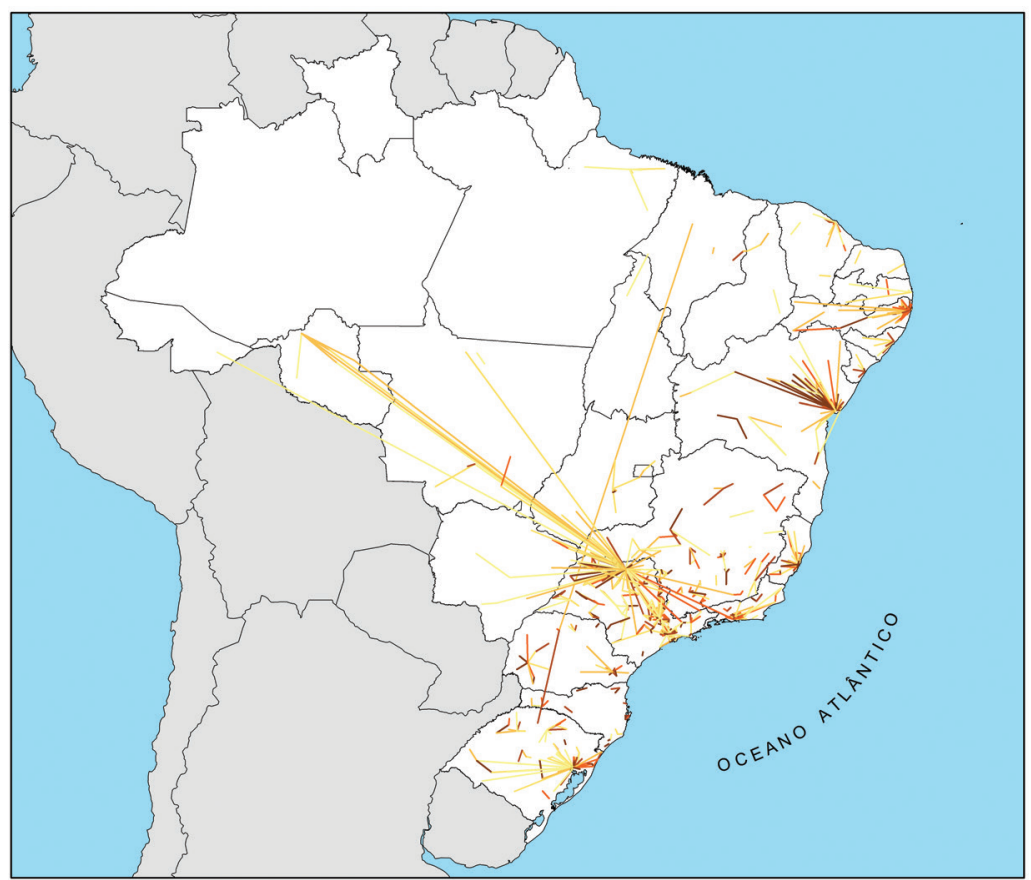

Legenda

Total de atendimentos atributo
$30-46$
$47-76$
$77-142$
- $143-303$
- $304-800$
- $801-12095$
$\square$ UF
América do Sul

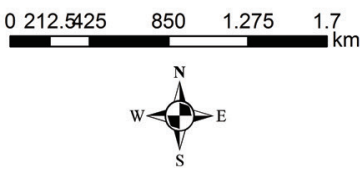


O volume de mamografias realizadas estava muito abaixo do esperado para a população feminina brasileira. Velasco e colaboradores (2014) avaliaram regionais de saúde no estado de Goiás e constataram que algumas não realizavam o exame de mamografia, com isso as mulheres que dispunham apenas do sistema público de saúde tinham de se deslocar de seu município de residência em busca de atendimento, o que em última análise sobrecarregava outros centros diagnósticos. Foi possível concluir que muitas das pacientes acabavam por não ter acesso ao procedimento por meio do sistema público de saúde.

\section{Alta complexidade: cirurgia oncológica de mama}

Assim como o apresentado nas mamografias, observa-se um volume baixo de cirurgias oncológicas de mama realizadas. Os vinte municípios listados com mais cirurgias oncológicas de mama no Brasil no período de 2010 a 2012 respondem por mais de 61\% do volume total no país. Possivelmente, esse número é subestimado já que muitas pacientes devem recorrer ao sistema privado de saúde quando se deparam com uma situação de diagnóstico de neoplasia mamária. Observando apenas o volume de mamografia, Lima-Costa e Matos (2007) ao analisar dados da Pesquisa Nacional por amostra de Domicílios (Pnad) concluíram que, entre as pacientes que detinham plano de saúde, cerca de 74\% realizaram o exame de mamografia, ao passo que entre as que dependiam apenas do serviço público essa proporção foi de 35\%. Essa busca pelo serviço privado deve repetir-se de forma mais acentuada para a cirurgia oncológica da mama que, no período, registrou em três anos apenas 22 mil procedimentos realizados pelo SUS. Observa-se que o município do Rio de Janeiro atendeu $10 \%$ das cirurgias, seguido de São Paulo, Recife, Fortaleza e Campinas. Esses cinco municípios concentram 32\% das cirurgias realizadas no território nacional. Além das capitais assinaladas na tabela, destacam-se os municípios de Barretos e Jaú no estado de São Paulo e Londrina no estado do Paraná (Tabela 5).

Quando observado o fluxo de pacientes para realização da cirurgia oncológica de mama no período de 2010 a 2012, observa-se que das 22 mil cirurgias ocorridas no período, $2 \%$ dos pacientes se deslocaram para realizá-las. O município de São Paulo recebeu mais 16,5\% do total, seguido de Vitória com 12\% e Jaú, Barretos e Recife, com 11\%, 11\% e 9\%, respectivamente.

Tabela 5 - Frequência e fluxo de pacientes para cirurgia oncológica de mama segundo municípios. Brasil - 2010 a 2012

\begin{tabular}{|c|c|c|c|c|c|c|c|}
\hline Municípios & $\begin{array}{c}\mathrm{N}^{\mathrm{o}} \mathrm{de} \\
\text { atendimentos }\end{array}$ & $\%$ & $\begin{array}{c}\% \\
\text { Acumulado }\end{array}$ & Municípios & $\begin{array}{l}\mathrm{N}^{0} \text { Não } \\
\text { residentes }\end{array}$ & $\%$ & $\begin{array}{c}\% \\
\text { Acumulado }\end{array}$ \\
\hline Rio de Janeiro & 2118 & 9,60 & 9,60 & São Paulo & 67 & 16,50 & 16,50 \\
\hline São Paulo & 1769 & 8,02 & 17,61 & Vitória & 47 & 11,58 & 28,08 \\
\hline Recife & 1433 & 6,49 & 24,11 & Jaú & 44 & 10,84 & 38,92 \\
\hline Fortaleza & 1079 & 4,89 & 29,00 & Barretos & 43 & 10,59 & 49,51 \\
\hline Campinas & 653 & 2,96 & 31,96 & Recife & 37 & 9,11 & 58,62 \\
\hline Barretos & 586 & 2,66 & 34,61 & Rio de Janeiro & 35 & 8,62 & 67,24 \\
\hline João Pessoa & 574 & 2,60 & 37,21 & Santos & 27 & 6,65 & 73,89 \\
\hline Belo Horizonte & 550 & 2,49 & 39,70 & Campinas & 19 & 4,68 & 78,57 \\
\hline
\end{tabular}


Tabela 5 - Frequência e fluxo de pacientes para cirurgia oncológica de mama segundo municípios. Brasil - 2010 a 2012 (cont.)

\begin{tabular}{|l|c|c|c|}
\hline \multicolumn{1}{|c|}{ Municípios } & $\begin{array}{c}\mathrm{N}^{\mathrm{o}} \text { de } \\
\text { atendimentos }\end{array}$ & $\%$ & $\begin{array}{c}\% \\
\text { Acumulado }\end{array}$ \\
\hline Natal & 509 & 2,31 & 42,01 \\
\hline Vitória & 509 & 2,31 & 44,32 \\
\hline Curitiba & 497 & 2,25 & 46,57 \\
\hline Porto Alegre & 468 & 2,12 & 48,69 \\
\hline Jaú & 451 & 2,04 & 50,73 \\
\hline Belém & 392 & 1,78 & 52,51 \\
\hline Teresina & 391 & 1,77 & 54,28 \\
\hline Manaus & 386 & 1,75 & 56,03 \\
\hline Brasília & 325 & 1,47 & 57,50 \\
\hline Londrina & 308 & 1,40 & 58,90 \\
\hline Maceió & 280 & 1,27 & 60,17 \\
\hline Goiânia & 280 & 1,27 & 61,44 \\
\hline
\end{tabular}

\begin{tabular}{|l|c|c|c|}
\hline \multicolumn{1}{|c|}{ Municípios } & $\begin{array}{c}\mathrm{N}^{0} \text { Não } \\
\text { residentes }\end{array}$ & $\%$ & $\begin{array}{c}\% \\
\text { Acumulado }\end{array}$ \\
\hline Curitiba & 12 & 2,96 & 81,53 \\
\hline Natal & 8 & 1,97 & 83,50 \\
\hline Porto Alegre & 8 & 1,97 & 85,47 \\
\hline Cabo Frio & 7 & 1,72 & 87,19 \\
\hline Campo Grande & 6 & 1,48 & 88,67 \\
\hline Belo Horizonte & 5 & 1,23 & 89,90 \\
\hline Santo André & 5 & 1,23 & 91,13 \\
\hline Botucatu & 4 & 0,99 & 92,12 \\
\hline Arapongas & 4 & 0,99 & 93,10 \\
\hline Campina & 4 & 0,99 & 94,09 \\
\hline Grande do Sul & 3 & 0,74 & 94,83 \\
\hline Belém & 3 & 0,74 & 95,57 \\
\hline Cascavel & & & \\
\hline
\end{tabular}

Fonte: SIH.

Na Figura 5 apresenta-se a distribuição gráfica do número de cirurgias oncológicas de mama segundo o município de atendimento no período de 2010 a 2012. Os quadrados proporcionais em vermelho destacam os municípios citados na tabela e que contam com a maior frequência de cirurgias. Os círculos proporcionais em amarelo indicam os demais municípios que fizeram cirurgias no período. Observa-se que partes das regiões Sudeste, Sul e litoral do Nordeste registram ocorrências de cirurgias de forma mais distribuída em seus municípios; no restante do país as frequências estão mais dispersas, localizadas principalmente nas capitais dos estados.

Observa-se na distribuição gráfica que nas regiões Sul, Sudeste e litoral do Nordeste alguns municípios polarizam o fluxo de pacientes, de uma forma mais regional ou microrregional, com poucas setas e intensidade. Também é possível verificar pessoas se deslocando das regiões Norte e CentroOeste em busca de atendimento no município de Barretos, formando um polo nacional. Apenas $2 \%$ dos pacientes para cirurgias oncológicas de mama buscaram atendimento em outros municípios, um número muito baixo considerando que a complexidade do procedimento é alta e não disponível na grande maioria de municípios do país. 
Figura 5 - Frequência e fluxo de pacientes para cirurgia oncológica de mama por municípios. Brasil -2010 a 2012

FLUXO DE ATENDIMENTOS PARA

"ALTA COMPLEXIDADE - CIRURGIA ONCOLÓGICA DE MAMA"

EM TODAS AS IDADES NO TRIÊNIO 2010-2012

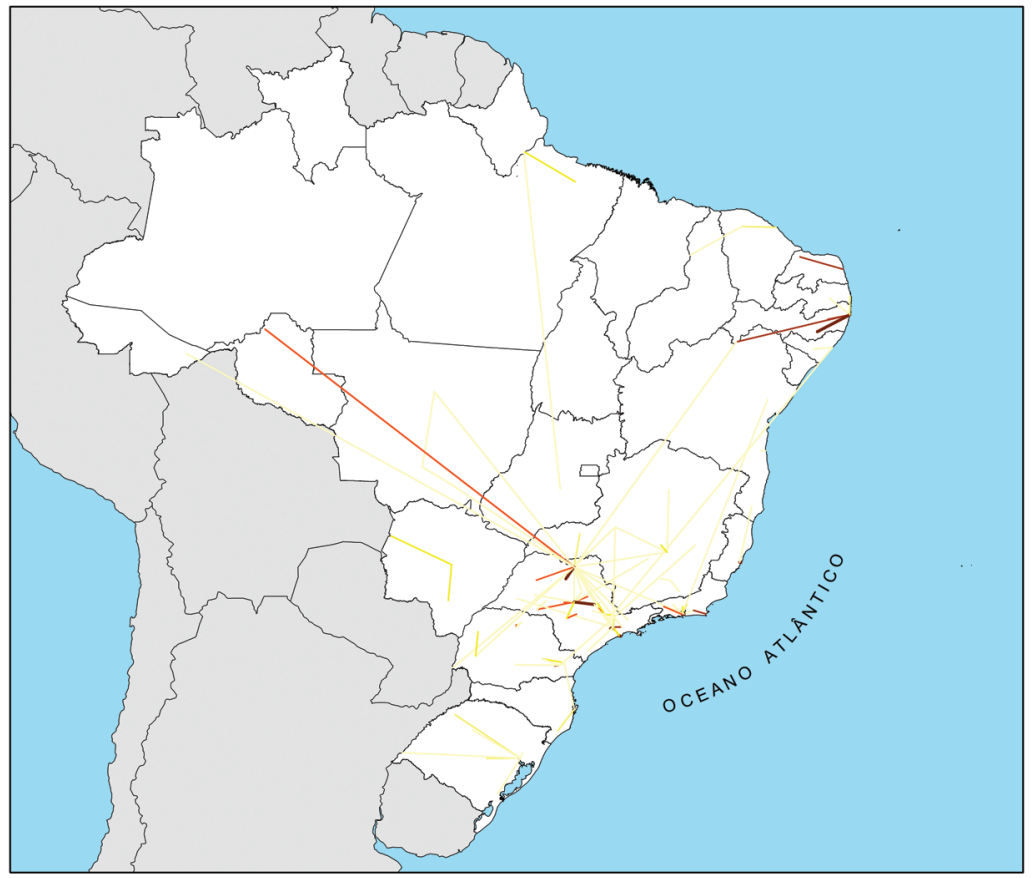

Legenda

atributo

1

2

3

$-4-6$

$-7-10$

$-11-46$

$\square$ UF

$\square$ América do Sul

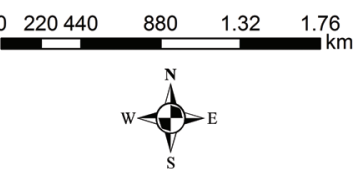

TOTAL DE ATENDIMENTOS PARA

"ALTA COMPLEXIDADE - CIRURGIA ONCOLÓGICA DE MAMA" EM TODAS AS IDADES NO TRIÊNIO 2010-2012

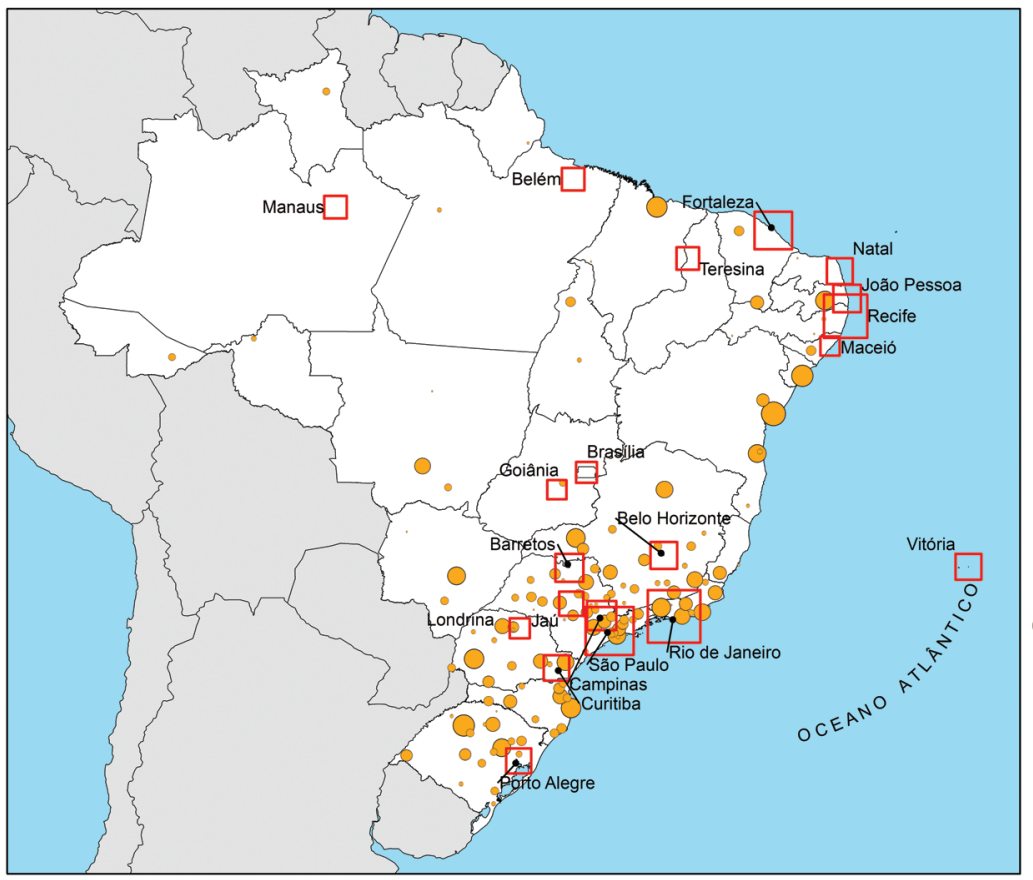

Legenda

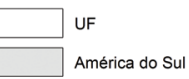

Símbolos proporcionais para frequência de internações

○ 280

- 140

- 70

20 municípios com maio número de internações

प 2.100

$\square \quad 1.050$

525

$\begin{array}{lllll}220440 & 880 & 1.32 & 1.76\end{array}$

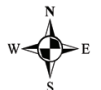




\section{Alta complexidade: angioplastia e revascularização do miocárdio}

Na Tabela 6 estão listados os vinte municípios que mais realizaram angioplastias no Brasil no período de 2010 a 2012. No período foram realizados 183.199 procedimentos e esses vinte municípios respondem por $51 \%$ do volume total de angioplastia no país. Observa-se que o município de São Paulo atendeu 12,3\% dos pacientes, seguido de Porto Alegre, Belo Horizonte, Passo Fundo e Fortaleza. Esses cinco municípios concentram $27 \%$ dos atendimentos realizados no território nacional. Além das capitais apresentadas na tabela, destacam-se os municípios de Passo Fundo, no interior do estado de Rio Grande do Sul, São José do Rio Preto e Ribeirão Preto, no interior do estado de São Paulo, Montes Claros e Juiz de Fora no interior de Minas Gerais, Sobral no estado do Ceará, Campina Grande do Sul, Arapongas e Ponta Grossa, no estado do Paraná.

Também são listados os vinte municípios do país que mais receberam pacientes de outros municípios para atendimento; totalizando quase $100 \%$ dos pacientes que tiveram que se deslocar em busca de atendimento. O município de São Paulo recebeu cerca de 36\% do total, seguido de Porto Alegre, com 17\%, São José (SC) e Rio de Janeiro com 6\%. Os municípios de Vila Velha (ES), Niterói (RJ) e Goiânia (GO) registraram importante número de pacientes oriundos de outros municípios.

Tabela 6 - Frequência de angioplastia, segundo municípios. Brasil - 2010 a 2012

\begin{tabular}{|c|c|c|c|c|c|c|c|}
\hline Municípios & $\begin{array}{c}\mathrm{N}^{\mathrm{o}} \text { de } \\
\text { atendimentos }\end{array}$ & $\%$ & $\begin{array}{c}\% \\
\text { Acumulado }\end{array}$ & Municípios & $\begin{array}{l}\mathrm{N}^{\circ} \text { Não } \\
\text { residentes }\end{array}$ & $\%$ & $\begin{array}{c}\% \\
\text { Acumulado }\end{array}$ \\
\hline São Paulo & 22.541 & 12,3 & 12,3 & São Paulo & 1.741 & 36,44 & 36,44 \\
\hline Porto Alegre & 10.644 & 5,8 & 18,11 & Porto Alegre & 811 & 16,97 & 53,41 \\
\hline Belo Horizonte & 5.812 & 3,2 & 21,29 & São José & 327 & 6,84 & 60,26 \\
\hline Passo Fundo & 5.640 & 3,08 & 24,37 & Rio de Janeiro & 297 & 6,22 & 66,47 \\
\hline Fortaleza & 5.602 & 3,06 & 27,42 & Vila Velha & 243 & 5,09 & 71,56 \\
\hline Curitiba & 5.562 & 3,04 & 30,46 & Niterói & 187 & 3,91 & 75,47 \\
\hline Goiânia & 4.242 & 2,32 & 32,77 & Goiânia & 169 & 3,54 & 79,01 \\
\hline Recife & 3.645 & 1,99 & 34,76 & Lajeado & 161 & 3,37 & 82,38 \\
\hline Rio de Janeiro & 3.258 & 1,78 & 36,54 & Recife & 150 & 3,14 & 85,52 \\
\hline Natal & 3.004 & 1,64 & 38,18 & Curitiba & 101 & 2,11 & 87,63 \\
\hline $\begin{array}{l}\text { São José do Rio } \\
\text { Preto }\end{array}$ & 2.755 & 1,5 & 39,69 & Santo André & 75 & 1,57 & 89,2 \\
\hline Montes Claros & 2.737 & 1,49 & 41,18 & Salvador & 69 & 1,44 & 90,64 \\
\hline Sobral & 2.624 & 1,43 & 42,61 & Marília & 44 & 0,92 & 91,57 \\
\hline Salvador & 2.433 & 1,33 & 43,94 & Belo Horizonte & 34 & 0,71 & 92,28 \\
\hline Ribeirão Preto & 2.265 & 1,24 & 45,18 & Cabo Frio & 34 & 0,71 & 92,99 \\
\hline $\begin{array}{l}\text { Campina Grande } \\
\text { do Sul }\end{array}$ & 2.179 & 1,19 & 46,37 & $\begin{array}{l}\text { Campina } \\
\text { Grande do Sul }\end{array}$ & 33 & 0,69 & 93,68 \\
\hline Arapongas & 1.967 & 1,07 & 47,44 & Rio Grande & 32 & 0,67 & 94,35 \\
\hline Juiz de Fora & 1.965 & 1,07 & 48,51 & Barra Mansa & 21 & 0,44 & 94,79 \\
\hline Maceió & 1.836 & 1 & 49,52 & Taubaté & 21 & 0,44 & 95,23 \\
\hline Ponta Grossa & 1.830 & 1 & 50,51 & Ijuí & 19 & 0,4 & 95,63 \\
\hline
\end{tabular}

Fonte: SIH. 
Na Figura 6, a distribuição gráfica do número de angioplastias segundo o município de atendimento no período de 2010 a 2012. Os quadrados proporcionais em vermelho destacam os municípios citados na tabela com a maior frequência de cirurgias. Nos círculos proporcionais em amarelo, os demais municípios que tiveram cirurgias de angioplastia no período. Observa-se que nas regiões Sudeste e Sul a frequência dos procedimentos está distribuída de forma que alguns municípios apresentam importante volume de procedimentos realizados; por outro lado, nas regiões Centro-Oeste, Norte e Nordeste apenas as capitais realizam o procedimento e na maioria delas o volume de atendimento é muito pequeno.

A distribuição gráfica do fluxo de angioplastia segundo o município de atendimento no período de 2010 a 2012 também é apresentada na figura. Nas regiões Sul, Sudeste e litoral do Nordeste algumas capitais estaduais recebem fluxo de pacientes. Nas regiões Sudeste, Sul e região litorânea do Nordeste são observados municípios que formam polos regionais, com exceção de São Paulo, que se mostra como importante polo nacional - o deslocamento dos pacientes é caracterizado por distâncias consideráveis percorridas para a obtenção do atendimento nesse município. Contudo, cabe ressaltar que o volume de pacientes deslocados em busca de atendimento é irrisório, quando consideramos que apenas 2,6\% tiveram que buscar atendimento fora do município de residência.

Figura 6 - Frequência e fluxo de angioplastia por municípios. Brasil - 2010 a 2012

FLUXO DE ATENDIMENTOS PARA "ALTA COMPLEXIDADE - ANGIOPLASTIA" EM TODAS AS IDADES NO TRIÊNIO 2010-2012

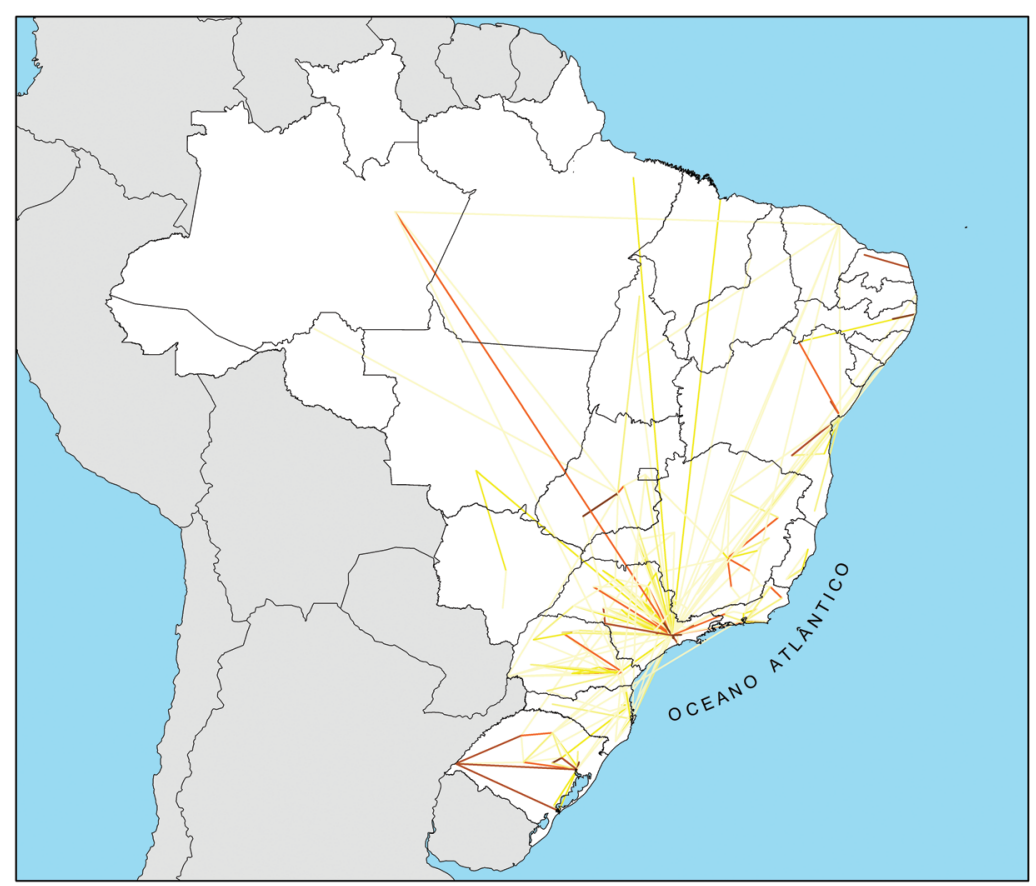

Legenda

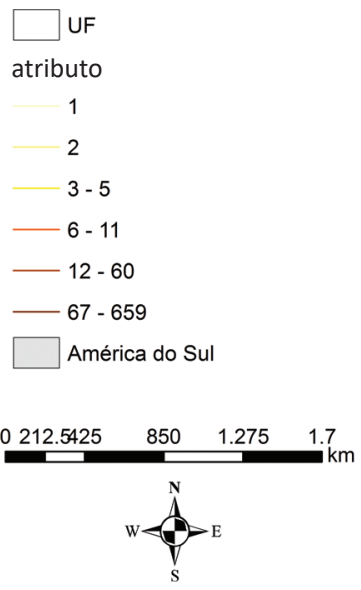


Figura 6 - Frequência e fluxo de angioplastia por municípios. Brasil - 2010 a 2012 (cont.)

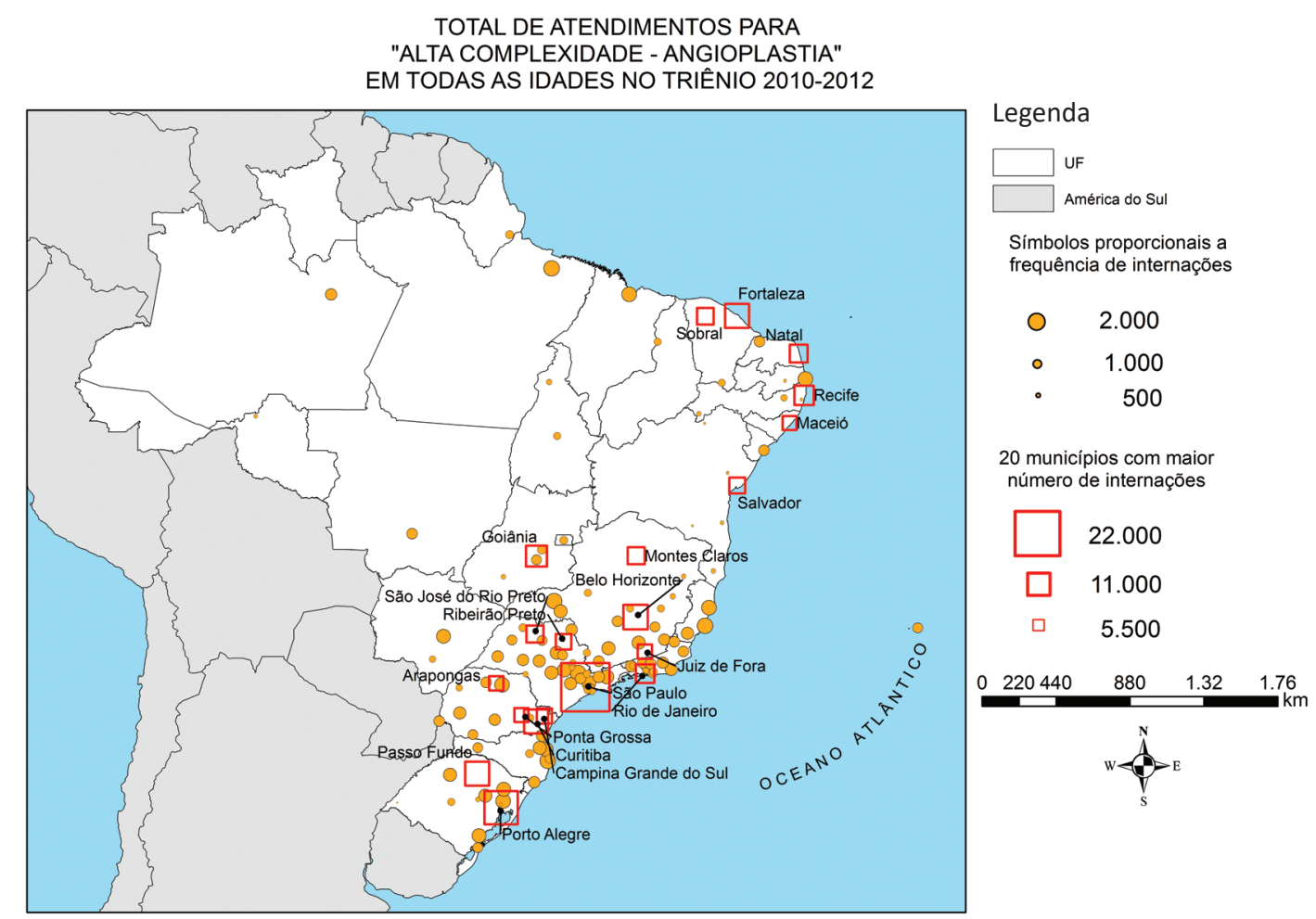

Na Tabela 7 estão listados os vinte municípios que mais realizaram cirurgias de revascularização do miocárdio no Brasil no período de 2010 a 2012. Tais municípios respondem por 60\% do volume total de cirurgias de revascularização do miocárdio no país. Observa-se que o município de São Paulo atendeu 21\% dos pacientes, seguido de Campina Grande do Sul, Porto Alegre, Belo Horizonte e Curitiba. Somente esses cinco municípios concentram cerca 35\% dos atendimentos realizados no território nacional.

Consta, ainda, na Tabela 7, o número de cirurgias de revascularização do miocárdio no município de destino de atendimento no período de 2010 a 2012, ou seja, são computados apenas pacientes que tiveram que se deslocar do seu município de residência. Das cerca de setenta mil cirurgias ocorridas no período, $6 \%$ dos pacientes tiveram que se deslocar para realizar a cirurgia. O conjunto dos vinte municípios citados na tabela atendeu cerca de $100 \%$ dos pacientes deslocados. O município de São Paulo recebeu 34\% do total, seguido de Campina Grande do Sul (PR) com 32\%, Porto Alegre, Rio de Janeiro e Recife, com 6\%, 5\% e 3,5\%, respectivamente. Os municípios de Campos dos Goitacazes (RJ), Goiânia e Vila Velha (ES) apresentam importante número de pacientes oriundos de outros municípios. 
Tabela 7 - Frequência e fluxo de pacientes para cirurgias de revascularização do miocárdio, segundo municípios. Brasil - 2010 a 2012

\begin{tabular}{|c|c|c|c|c|c|c|c|}
\hline Municípios & $\begin{array}{c}\mathrm{N}^{\mathrm{o}} \text { de } \\
\text { atendimentos }\end{array}$ & $\%$ & $\begin{array}{c}\% \\
\text { Acumulado }\end{array}$ & Municípios & $\begin{array}{l}\mathrm{N}^{\circ} \text { Não } \\
\text { residentes }\end{array}$ & $\%$ & $\begin{array}{c}\% \\
\text { Acumulado }\end{array}$ \\
\hline São Paulo & 14.417 & 20,54 & 20,54 & São Paulo & 1.392 & 33,77 & 33,77 \\
\hline $\begin{array}{l}\text { Campina } \\
\text { Grande do Sul }\end{array}$ & 2.936 & 4,18 & 24,73 & $\begin{array}{r}\text { Campina } \\
\text { Grande do Sul }\end{array}$ & 1.318 & 31,97 & 65,74 \\
\hline Porto Alegre & 2.650 & 3,78 & 28,5 & Porto Alegre & 241 & 5,85 & 71,59 \\
\hline Belo Horizonte & 2.160 & 3,08 & 31,58 & Rio de Janeiro & 199 & 4,83 & 76,42 \\
\hline Curitiba & 2.013 & 2,87 & 34,45 & Recife & 141 & 3,42 & 79,84 \\
\hline Recife & 1.960 & 2,79 & 37,24 & $\begin{array}{r}\text { Campos dos } \\
\text { Goytacazes }\end{array}$ & 110 & 2,67 & 82,51 \\
\hline Rio de Janeiro & 1.746 & 2,49 & 39,73 & Goiânia & 109 & 2,64 & 85,15 \\
\hline Arapongas & 1.743 & 2,48 & 42,22 & Vila Velha & 82 & 1,99 & 87,14 \\
\hline Fortaleza & 1.731 & 2,47 & 44,68 & Curitiba & 72 & 1,75 & 88,89 \\
\hline Goiânia & 1.333 & 1,9 & 46,58 & São José & 61 & 1,48 & 90,37 \\
\hline Salvador & 1.319 & 1,88 & 48,46 & Salvador & 53 & 1,29 & 91,65 \\
\hline Teresina & 1.164 & 1,66 & 50,12 & Belo Horizonte & 41 & 0,99 & 92,65 \\
\hline Campo Grande & 1.100 & 1,57 & 51,69 & Arapongas & 41 & 0,99 & 93,64 \\
\hline Natal & 1.022 & 1,46 & 53,14 & Lajeado & 38 & 0,92 & 94,57 \\
\hline Montes Claros & 959 & 1,37 & 54,51 & Rio Grande & 29 & 0,7 & 95,27 \\
\hline Belém & 885 & 1,26 & 55,77 & Niterói & 27 & 0,66 & 95,92 \\
\hline Ponta Grossa & 779 & 1,11 & 56,88 & Marília & 24 & 0,58 & 96,51 \\
\hline Bauru & 745 & 1,06 & 57,94 & Nova Friburgo & 16 & 0,39 & 96,89 \\
\hline Vila Velha & 741 & 1,06 & 59 & Ipatinga & 15 & 0,36 & 97,26 \\
\hline Criciúma & 695 & 0,99 & 59,99 & Bauru & 13 & 0,32 & 97,57 \\
\hline
\end{tabular}

Fonte: SIH.

No primeiro mapa da Figura 7, apresenta-se a distribuição gráfica do número de cirurgias de revascularização do miocárdio segundo o município de atendimento no período de 2010 a 2012. Os quadrados proporcionais em vermelho destacam os municípios citados na tabela com a maior frequência de internações. Os círculos proporcionais em amarelo apresentam os demais municípios que tiveram internação cirúrgica realizada no período. Observa-se que nas regiões Sudeste, Sul e litoral do Nordeste estão concentrados os procedimentos realizados no período.

No segundo mapa, a distribuição gráfica do fluxo de cirurgias de revascularização do miocárdio sugere que nas regiões Sul, Sudeste e litoral do Nordeste do país alguns municípios polarizam o fluxo de pacientes e formam polos regionais, a exceção de São Paulo que se mostra como um polo nacional onde se observa que são percorridas distâncias consideráveis para a obtenção do atendimento. Contudo, o volume de pacientes deslocados é muito pequeno. 
Figura 7 - Frequência e fluxo de cirurgias de revascularização do miocárdio, segundo municípios para atendimento. Brasil - 2010 a 2012

FLUXO DE ATENDIMENTOS PARA

"ALTA COMPLEXIDADE - CIRURGIA DE REVASCULARIZAÇÃO DO MIOCÁRDIO" EM TODAS AS IDADES NO TRIÊNIO 2010-2012

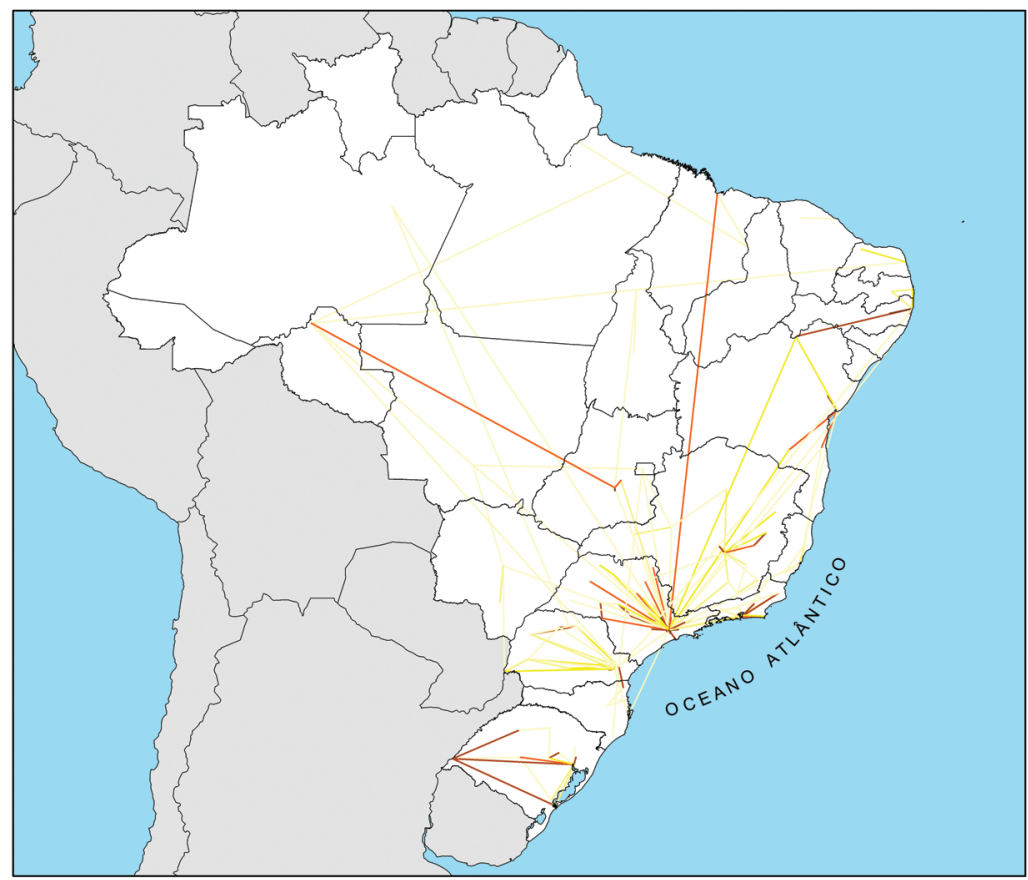

Legenda

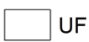

atributo

1

2

$-3-5$

$-6-11$

$-12-60$

$-67-659$

América do Sul

212.5425

$850 \quad 1.275$

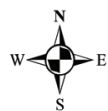

TOTAL DE ATENDIMENTOS PARA

"ALTA COMPLEXIDADE - CIRURGIA DE REVASCULARIZAÇÃO DO MIOCÁRDIO" EM TODAS AS IDADES NO TRIÊNIO 2010-2012

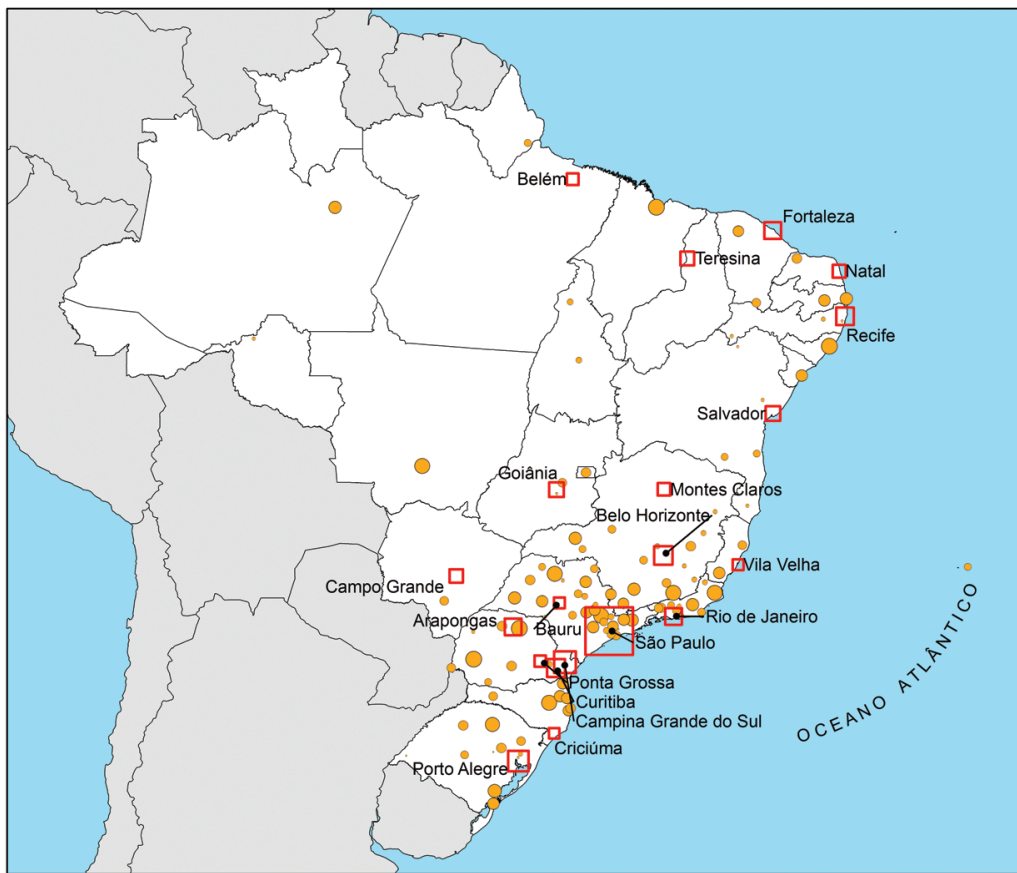

\section{Legenda}

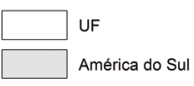

Símbolos proporcionais a frequência de internações

$\begin{array}{cc}\circ & 700 \\ \circ & 350 \\ \circ & 175\end{array}$

20 municípios com maior número de internações

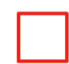

15.000

7.500

$\square \quad 3.500$

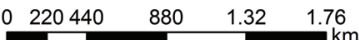


No Brasil, o número total de cirurgias de revascularização do miocárdio no período de 2010 a 2012 foi de 70.175 cirurgias. Se considerarmos o número total de angioplastias e de cirurgias de revascularização de miocárdio, temos que no Brasil no período entre 2010 a 2012 foram realizados 253.374 procedimentos, cerca de $28 \%$ das cirurgias coronárias por meio de revascularização do miocárdio e $72 \%$ por angioplastias, enquanto que no mundo, em 1999, essa proporção foi de $35 \%$ e 65\%, respectivamente (OECD, 2003).

\section{Alta complexidade: cirurgia ortopédica do quadril}

As intervenções cirúrgicas no quadril estão relacionadas, em sua maioria, a fraturas oriundas de quedas e osteoporose.

Na Tabela 8 listam-se os vinte municípios que realizaram o maior número de cirurgias ortopédicas de quadril no Brasil no período de 2010 a 2012. Tais municípios respondem por mais de 40\% do volume total no país. Observa-se que o município de São Paulo atendeu 9\% das cirurgias ortopédicas, seguido de Belo Horizonte, Rio de Janeiro, Porto Alegre e Fortaleza. Esses cinco municípios concentram quase um terço das cirurgias realizadas no território nacional. Além das capitais apresentadas na tabela, destacam-se os municípios de Passo Fundo, Canoas e Rio Grande, no Rio Grande do Sul; Sorocaba, São José do Rio Preto, Bauru e Ribeirão Preto, no estado de São Paulo; e Cascavel e Campina Grande do Sul, no Paraná.

Consta, ainda, o número de cirurgias ortopédicas de quadril para pacientes que tiveram que se deslocar do seu município de residência. Das 51 mil cirurgias ocorridas no período, em 12\% houve deslocamento dos pacientes. O conjunto dos vinte municípios citados atendeu $62 \%$ dos pacientes deslocados. Os municípios de São Paulo, Rio de Janeiro e Belo Horizonte receberam 11\% do total, cada um, seguidos de Porto Alegre com 5\% e Vitória 2,7\%. Outros municípios que apresentaram um número importante de atenção a não residentes foram: Curitiba, Rio Grande (RS) e Mogi das Cruzes (SP).

Tabela 8 - Frequência e fluxo de pacientes para cirurgia ortopédica do quadril, segundo municípios. Brasil - 2010 a 2012

\begin{tabular}{|c|c|c|c|c|c|c|c|}
\hline Municípios & $\begin{array}{c}\mathrm{N}^{\mathrm{o}} \mathrm{de} \\
\text { atendimentos }\end{array}$ & $\%$ & $\begin{array}{c}\% \\
\text { Acumulado }\end{array}$ & Municípios & $\begin{array}{l}\mathrm{N}^{\circ} \text { não } \\
\text { residentes }\end{array}$ & $\%$ & $\begin{array}{c}\% \\
\text { Acumulado }\end{array}$ \\
\hline São Paulo & 4.574 & 8,95 & 8,95 & São Paulo & 683 & 11,13 & 11,13 \\
\hline Belo Horizonte & 2.587 & 5,06 & 14,01 & Rio de Janeiro & 680 & 11,09 & 22,22 \\
\hline Rio de Janeiro & 2.563 & 5,02 & 19,03 & Belo Horizonte & 663 & 10,81 & 33,03 \\
\hline Porto Alegre & 1.375 & 2,69 & 21,72 & Porto Alegre & 313 & 5,10 & 38,13 \\
\hline Fortaleza & 1.001 & 1,96 & 23,68 & Vitória & 164 & 2,67 & 40,81 \\
\hline Curitiba & 943 & 1,85 & 25,52 & Curitiba & 153 & 2,49 & 43,30 \\
\hline Salvador & 888 & 1,74 & 27,26 & Rio Grande & 143 & 2,33 & 45,63 \\
\hline Natal & 732 & 1,43 & 28,69 & $\begin{array}{l}\text { Mogi das } \\
\text { Cruzes }\end{array}$ & 98 & 1,60 & 47,23 \\
\hline Goiânia & 677 & 1,32 & 30,02 & Natal & 88 & 1,43 & 48,66 \\
\hline
\end{tabular}


Tabela 8 - Frequência e fluxo de pacientes para cirurgia ortopédica do quadril, segundo municípios. Brasil - 2010 a 2012 (cont.)

\begin{tabular}{|c|c|c|c|c|c|c|c|}
\hline Municípios & $\begin{array}{c}\mathrm{N}^{\mathrm{o}} \mathrm{de} \\
\text { atendimentos }\end{array}$ & $\%$ & $\begin{array}{c}\% \\
\text { Acumulado }\end{array}$ & Municípios & $\begin{array}{l}\mathrm{N}^{\mathrm{o}} \text { não } \\
\text { residentes }\end{array}$ & $\%$ & $\begin{array}{c}\% \\
\text { Acumulado }\end{array}$ \\
\hline Passo Fundo & 645 & 1,26 & 31,28 & Passo Fundo & 88 & 1,43 & 50,10 \\
\hline Rio Grande & 604 & 1,18 & 32,46 & Sorocaba & 85 & 1,39 & 51,48 \\
\hline Sorocaba & 532 & 1,04 & 33,50 & Cuiabá & 84 & 1,37 & 52,85 \\
\hline Vitória & 498 & 0,97 & 34,48 & $\begin{array}{l}\text { Presidente } \\
\text { Prudente }\end{array}$ & 81 & 1,32 & 54,17 \\
\hline $\begin{array}{l}\text { São José do } \\
\text { Rio Preto }\end{array}$ & 461 & 0,90 & 35,38 & Goiânia & 80 & 1,30 & 55,48 \\
\hline Teresina & 438 & 0,86 & 36,24 & Taubaté & 74 & 1,21 & 56,68 \\
\hline Canoas & 429 & 0,84 & 37,08 & Santo André & 73 & 1,19 & 57,87 \\
\hline Cascavel & 421 & 0,82 & 37,90 & Campinas & 71 & 1,16 & 59,03 \\
\hline $\begin{array}{l}\text { Campina } \\
\text { Grande do Sul }\end{array}$ & 416 & 0,81 & 38,72 & $\begin{array}{l}\text { Cabo de Santo } \\
\text { Agostinho }\end{array}$ & 70 & 1,14 & 60,17 \\
\hline Bauru & 412 & 0,81 & 39,52 & Paulista & 69 & 1,12 & 61,30 \\
\hline Ribeirão Preto & 405 & 0,79 & 40,31 & Tubarão & 69 & 1,12 & 62,42 \\
\hline
\end{tabular}

Fonte: SIH.

Na Figura 8, por meio da distribuição gráfica do número de cirurgias ortopédicas do quadril, segundo o município de atendimento, no período de 2010 a 2012 se observa que partes das regiões Sudeste, Sul e litoral do Nordeste apresentam frequências de cirurgias de forma mais concentrada em seus municípios; no restante do país as frequências se mostram mais dispersas, localizadas principalmente nas capitais dos estados. Na mesma figura é apresentada a distribuição gráfica do fluxo de cirurgia ortopédica do quadril segundo o município de atendimento no período de 2010 a 2012, observando-se que a cidade do Rio de Janeiro forma um polo nacional. 
Figura 8 - Frequência e fluxo de pacientes em cirurgia ortopédica de quadril adulto por municípios. Brasil - 2010 a 2012

FLUXO DE ATENDIMENTOS PARA

"ALTA COMPLEXIDADE - CIRURGIA ORTOPÉDICA DO QUADRIL" EM TODAS AS IDADES NO TRIÊNIO 2010-2012

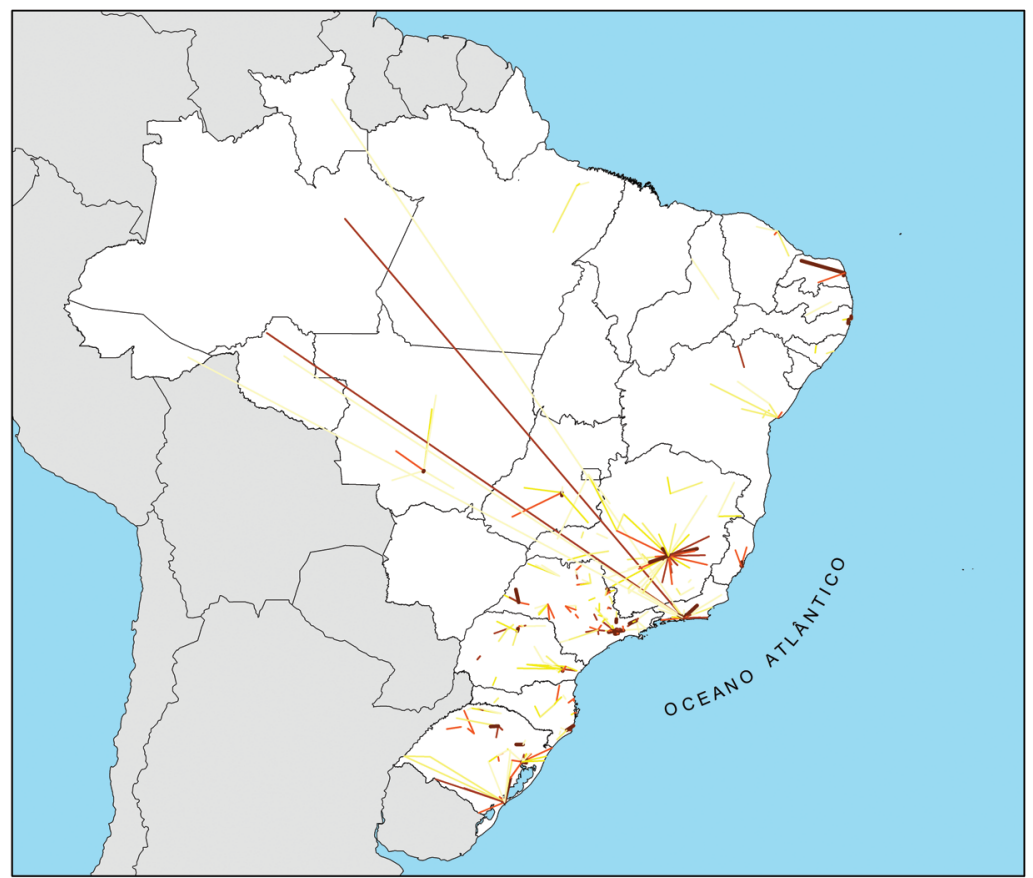

Legenda

atributo

5

$6-7$

$8-10$

$-11-14$

$-15-23$

$-24-128$

$\square$ UF

$\square$ América do Sul

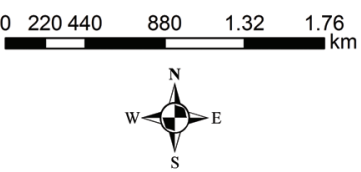

TOTAL DE ATENDIMENTOS PARA

"ALTA COMPLEXIDADE - CIRURGIA ORTOPÉDICA DO QUADRIL" EM TODAS AS IDADES NO TRIÊNIO 2010-2012

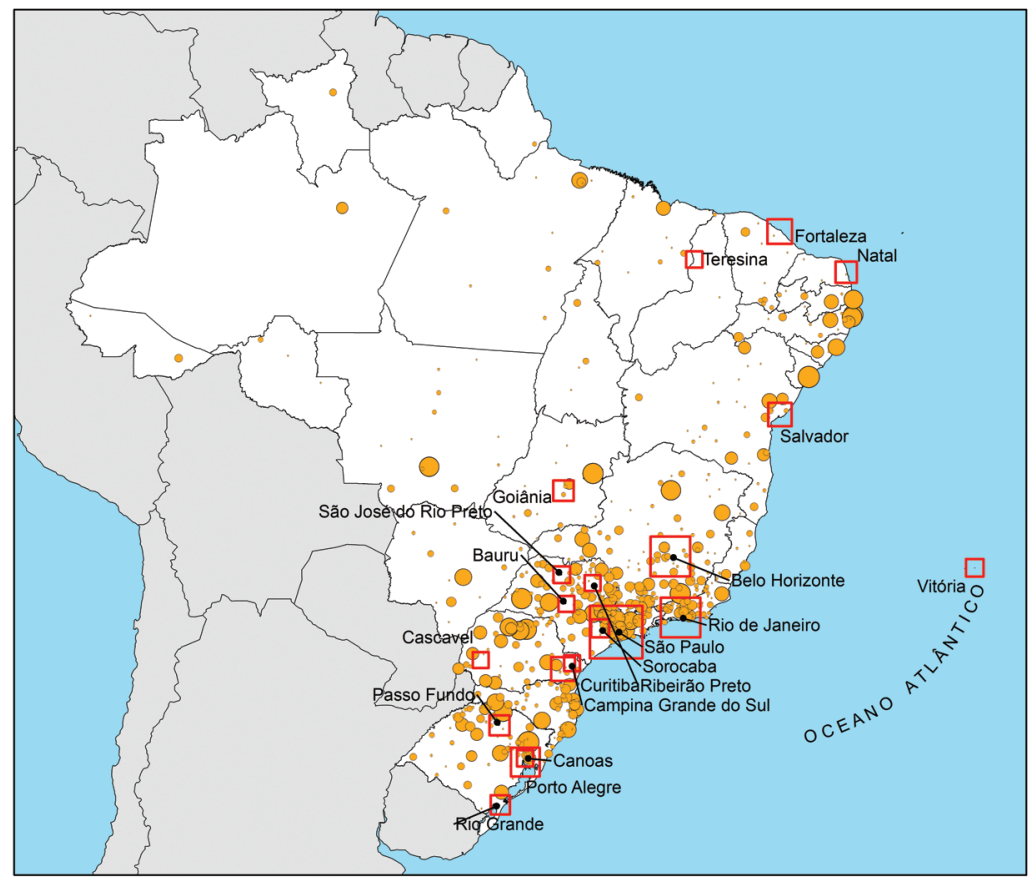

Legenda

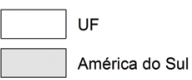

Símbolos proporcionais para frequência de internações

○ 360

- 180

- 90

20 municípios com maior número de internações
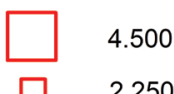

$\square$

1.125
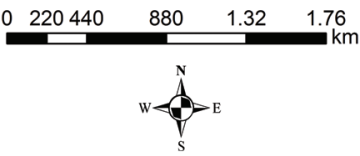


\section{Conclusões}

Como conclusão, é possível afirmar que os municípios mais populosos se encontram, na maioria das vezes, presentes na listagem dos primeiros vinte municípios, quando considerado o volume de internações de alta complexidade. Embora as capitais estejam presentes em quase todas as listagens de volume e de municípios-polo, verificam-se municípios em que o tamanho da população foi determinante para a inclusão nessas listagens. Tais casos ocorrem mais comumente nas internações de baixa-média complexidade. Entretanto, alguns municípios de médio porte populacional se caracterizam como referência para alguns subgrupos de internação, principalmente aqueles de alta complexidade. Os municípios que concentram as internações de maior complexidade apresentam maior percentual de atendimento a não residentes.

A concentração de atendimentos é diretamente relacionada à sua complexidade, ou seja, quanto mais complexo, maior a concentração. De modo geral, é possível classificar os fluxos de pacientes segundo os procedimentos analisados e as distâncias percorridas da seguinte forma:

- Internações de baixa-média complexidade apresentam pequenas distâncias percorridas pelos pacientes e conformam polos intraestaduais.

- Internações de alta complexidade e procedimentos diagnósticos e terapêuticos apresentam fluxos intensos e distâncias maiores, variando entre especialidade e tipo de procedimento realizado, indicando a existências de polos nacionais.

Nos procedimentos de alta complexidade, observa-se que vinte municípios, em geral, são responsáveis por mais de 50\% das internações, independentemente da especialidade analisada. Ou seja, no país, esses vinte municípios são referência para atendimento de alta complexidade.

Os polos para atendimento de cirurgia ortopédica do quadril parecem coincidir com os de neurocirurgia em algumas regiões do país, sobretudo no Sudeste e Sul. É importante ressaltar que as cirurgias ortopédicas de joelho não apresentam os mesmos polos que as cirurgias ortopédicas de quadril. ${ }^{2}$ Os municípios principais com internação para realização de angioplastia e revascularização do miocárdio também são os mesmos polos de atendimento. Considerando as internações oncológicas em geral, destacam-se os polos de municípios no interior do estado de São Paulo, região de Barretos, Ribeirão Preto e São José do Rio Preto, além de municípios no oeste do estado do Paraná.

Os fluxos de internação para baixa-média complexidade geralmente descrevem pequenos trajetos percorridos para atendimento. Em procedimentos cirúrgicos, os fluxos parecem ser mais intensos em comparação aos procedimentos clínicos.

Quanto aos procedimentos diagnósticos e terapêuticos, é importante analisá-los separadamente. No caso da mamografia, observa-se além de grandes capitais como São Paulo, Rio de Janeiro, Salvador, Recife, Fortaleza e Vitória, algumas cidades de médio porte como Barretos, Joinville, Campinas, Guarulhos e São Bernardo do Campo que se destacam pelo alto volume de atendimentos.

\footnotetext{
${ }^{2}$ Ver Relatório de pesquisa do projeto Saúde Amanhã (Xavier et al., 2014).
} 
O comportamento do fluxo de pacientes pode ser explicado como resultado do próprio processo de urbanização maciça, que embora produza cinturões de miséria em uma escala micro, acaba por facilitar o acesso de grandes contingentes populacionais em busca de recursos. Em alguns casos a oferta maior de serviços especializados em cidades de maior porte ocorre dentro do contexto de conurbação, ou seja, a extensão contínua e eventual encontro das áreas urbanizadas de dois ou mais municípios (Monte-Mor et al., 1997), como no caso da região metropolitana de São Paulo. Essa característica é observada para além de áreas metropolitanas dentro de uma mesma unidade da federação, como no caso de Petrolina e Juazeiro na região Nordeste do país, e tantos outros centros populacionais limítrofes entre estados. Nesse caso, deve-se observar a resolução apresentada para a nova regionalização da saúde, que entre outros aspectos contempla a criação de regiões de saúde interestaduais, compostas por municípios limítrofes de mais de um estado, instituídas por ato conjunto dos respectivos estados em articulação com os municípios (Brasil, 2011).

O desenvolvimento econômico nem sempre representa uma melhoria linear para o setor Saúde, e é exatamente quando isso não ocorre que se observa situação de desigualdade. Em outras situações, a lógica econômica pode não expressar a melhoria no setor Saúde, tampouco a centralidade para o serviço de saúde. Oliveira e colaboradores (2011) evidenciaram, através da avaliação de fluxos de pacientes para tratamento de câncer, que municípios como Barretos e Jaú no interior do estado de São Paulo, por exemplo, apresentaram grande relevância para o tratamento oncológico e representam polos de atendimento de referência para o país.

A rede de deslocamento de pacientes pode servir de subsídio para descrever como ocorrem as conexões e como se expressa a distribuição do atendimento à saúde, e também para descrever desigualdades geográficas no acesso, explicadas seja pela disponibilidade de serviços, seja pela estruturação da oferta que marginaliza (no sentido espacial da palavra) e priva populações mais pobres dos ganhos que o desenvolvimento econômico traz ao espaço social.

Por último, é importante considerar que várias redes de serviços de saúde estão sobrepostas para diferentes tipos de atendimento e essas são informações fundamentais, provavelmente usadas, para a definição das regiões de saúde pelas unidades da federação, tanto pela possibilidade de incluir municípios-polos e os deslocamentos de pacientes e, sobretudo, para orientar o encaminhamento de pacientes residentes em outras regiões de saúde. Na perspectiva de complexidade do atendimento torna-se inviável implantar serviços de alta complexidade em todos os municípios e regiões de saúde do país. Dessa forma, uma alternativa seria aumentar a oferta de atendimento de alta complexidade em grandes centros e tornar possível e otimizado o deslocamento dos pacientes em busca de atendimentos. 


\section{Referências}

BONDY, J. A. \& MURTY, U. S. R. Graph Theory with Applications. London: Macmillan, 1976.

BRASIL. Presidência da República. Lei n. 8080, de 19 set. 1990. Dispõe sobre as condições para a promoção, proteção e recuperação da saúde, a organização e o funcionamento dos serviços correspondentes e dá outras providências. Disponível em <www.planalto.gov.br/ccivil_03/leis/18080.htm>. Acesso em: 20 abr. 2015.

BRASIL. Decreto n. 7.508, de 28 jun. 2011. Regulamenta a Lei n. 8.080, de 19 set. 1990, para dispor sobre a organização do Sistema Único de Saúde - SUS, o planejamento da saúde, a assistência à saúde e a articulação interfederativa, e dá outras providências. Brasília, Diário Oficial da União, 2011. Disponível em: <www.planalto. gov.br/ccivil_03/_ato2011-2014/2011/decreto/D7508.htm>. Acesso em: 20 abr. 2015.

DEPARTAMENTO DE INFORMATICA DO SUS (DATASUS). Departamento de Informatica do SUS. Disponível em: <http://datasus.saude.gov.br/>.

DIESTEL, R. Graph Theory. 3. ed. New York: Springer, 2005.

FUNDAÇÃO OSWALDO CRUZ. Saúde Amanhã: o projeto, 2013. Disponível em: <www.saudeamanha.fiocruz. br>. Acesso em: 20 abr. 2015.

JACOBS, B. et al. Addressing access barriers to health services: an analytical framework for selecting appropriate interventions in low-income Asian countries. Health Policy and Planning, 27: 288-300, 2012.

LIMA-COSTA, M. F. \& MATOS, D. L. Prevalência e fatores associados à realização da mamografia na faixa etária de 50-69 anos: um estudo baseado na Pesquisa Nacional por Amostra de Domicílios (2003). Cadernos de Saúde Pública, 23(7): 1.665-1.673, 2007.

LIMA-COSTA, M. F.; PEIXOTO, S. V.; GIATTI, L. Tendências da mortalidade entre idosos brasileiros (1980-2000). Epidemiologia e Serviços de Saúde, 13: 217-228, 2004.

LIMA, L. et al. Regionalização da saúde no Brasil. In: GIOVANELLA, L. et al. (Orgs.). Políticas e Sistemas de Saúde no Brasil. 2. ed. rev. e ampl. Rio de Janeiro: Editora Fiocruz, 2012.

MONTE-MÓR, R. L. M. et al. Ocupação do Território e Estrutura Urbana. In: PAULA, J. A. (Coord.). Biodiversidade, População e Economia: uma região de mata atlântica. Belo Horizonte: UFMG/Cedeplar, ECMCX, PADCT/Ciamb, 1997.

NORONHA, J. \& PEREIRA, T. Princípios do sistema de saúde brasileiro. In: GADELHA, P.; CARVALHO, J. N. \& PEREIRA, T. R. (Orgs.). A Saúde no Brasil em 2030: diretrizes para a prospeç̧ão estratégica do sistema de saúde brasileiro. Rio de Janeiro: Editora Fiocruz, Ipea, Ministério da Saúde, Secretaria de Assuntos Estratégicos da Presidência da República, 2013.

NYSTUEN, J. D. \& DACEY, M. F. A graph theory interpretation of nodal regions. Papers and Proceedings of the Regional Science Association, 7: 29-42, 1961.

OLIVEIRA, E. X. G.; CARVALHO, M. S. \& TRAVASSOS, C. Territórios do Sistema Único de Saúde - mapeamento das redes de atenção hospitalar. Cadernos de Saúde Pública, 20(2): 386-402, 2004.

OLIVEIRA, E. X. G.; TRAVASSOS, C. \& CARVALHO, M. S. Acesso à internação hospitalar nos municípios brasileiros em 2000: territórios do Sistema Único de Saúde. Cadernos de Saúde Pública, 20, supl. 2: S298-309, 2004.

OLIVEIRA, E. X. G. et al. Acesso à assistência oncológica: mapeamento dos fluxos origem-destino das internações e dos atendimentos ambulatoriais. O caso do câncer de mama. Cadernos de Saúde Pública, 27(2): 317-326, 2011.

ORGANISATION FOR ECONOMIC CO-OPERATION AND DEVELOPMENT (OECD). Study of cross-national differences in the treatment, costs and outcomes of ischaemic heart disease. OECD Health Working Papers, 3. Paris: OECD, 2003. (Delsa/Elsa/WD/HEA, 2003) 
OUVERNEY, A. M. \& NORONHA, J. Modelos de organização e gestão da atenção à saúde: redes locais, regionais e nacionais. In: GADELHA, P.; CARVALHO, J. N. \& PEREIRA, T. R. (Orgs.). A Saúde no Brasil em 2030: diretrizes para a prospecção estratégica do sistema de saúde brasileiro. Rio de Janeiro: Editora Fiocruz, Ipea, Ministério da Saúde, Secretaria de Assuntos Estratégicos da Presidência da República, 2013.

SISTEMA DE INFORMAÇÃO HOSPITALAR DO SUS (SIH). Disponível em:<http://www2.datasus.gov.br/ DATASUS/index.php?area $=0901>$.

UNGLERT, C. V. S.; ROSENBURG, C. P. \& JUNQUEIRA, C. B. Acesso aos serviços de saúde: uma abordagem de geografia em saúde pública. Revista de Saúde Pública, 21(5): 439-446, 1987.

VELASCO, W. et al. Acesso ao SUS: modelagem de indicadores de fluxos dos atendimentos de média complexidade - o caso da mamografia. In: CONGRESSO BRASILEIRO DE ENGENHARIA BIOMÉDICA, XXIV, 13-17 out. 2014, Uberlândia.

XAVIER, D. R. et al. Polos e fluxos de deslocamento de pacientes para internação hospitalar e procedimentos selecionados no Sistema Único de Saúde. Relatório de Pesquisa Projeto Saúde Amanhã. Rio de Janeiro: Fiocruz, 2014. 